\title{
Deuterium retention in dense and disordered nanostructured tungsten
}

\author{
coatings
}

O.V. Ogorodnikova ${ }^{1}$, C. Ruset ${ }^{2}$, D. Dellasega ${ }^{3,4}$, A. Pezzoli $^{3}$, M. Passoni ${ }^{3,4}$, K. Sugiyama ${ }^{5}$, Yu. Gasparyan $^{1}$, V. Efimov ${ }^{1}$

${ }^{1}$ National Research Nuclear University MEPhI (Moscow Engineering Physics Institute), Moscow, Kashirskoe sh. 31, 115409, Russia

${ }^{2}$ National Institute for Laser, Plasma and Radiation Physics P.O.Box MG-36, Magurele-Bucharest, Romania

${ }^{3}$ Dipartimento di Energia, Politecnico di Milano - Milano, Italy

${ }^{4}$ Istituto di Fisica del Plasma, CNR, EURATOM-ENEA-CNR Association - Milano, Italy

${ }^{5}$ Max-Planck-Institut für Plasmaphysik, EURATOM-Association, Boltzmannstraße 2, 85748 Garching, Germany

\section{Abstract}

A systematic and attentive comparison of the deuterium (D) retention in tungsten (W) coatings with different nano-crystalline structures after the plasma exposure in comparison with polycrystalline tungsten (PCW) is presented. While a wide database is available for PCW, only a few data about the D retention in coatings with different structures exist. The D retention in $\mathrm{W}$ coatings produced by three different deposition techniques on different substrates was studied with respect to the influence of (a) coating crystallite size, (b) coating thickness, (c) specimen temperature during D plasma exposure, (d) presence of argon (Ar) used as working gas during the coating deposition and (e) substrate material. It was shown that the variation of the processing parameters, such as temperature, deposition rate, $\mathrm{Ar}$ implantation, etc. even within one deposition method results in different grain size distributions and structure of coating and has a significant effect on the D retention. It was revealed that the substrate material and the presence of $\mathrm{Ar}$ in a coating play a minor role in the $\mathrm{D}$ retention in the coating. It was shown that both the $\mathrm{D}$ concentration and the $\mathrm{D}$ retention 
in coatings drastically increase with decreasing the grain size. Consequently, in the case of using of $\mathrm{W}$ coating as a protective layer of a structural material, a compromise in the development of nanostructured tungsten films is necessary to keep the hydrogen isotope concentration at an acceptable level.

Keywords: nano-structured tungsten coating, deuterium retention, grain size, plasma 


\section{Introduction}

A prediction of fuel retention in plasma-facing materials (PFMs) for ITER and future fusion reactors depends on the understanding of the fundamental hydrogen isotope retention mechanisms in these materials. Tungsten (W) is a promising material because of the high melting point, low sputtering rate and low hydrogen solubility. A lot of effort has been devoted to investigating deuterium (D) retention in undamaged [1-7] and radiation-damaged [8-13] polycrystalline tungsten (PCW). Those studies confirmed that the $\mathrm{D}$ retention in undamaged PCW should be smaller compared to the D retention expected for other candidates, e.g. carbon and beryllium, which is a positive aspect with respect to the control of in-vessel tritium inventory [14-17]. However, the D retention at radiation-induced defects in PCW can be a concern [11-13]. Moreover, the D retention in $\mathrm{W}$ coatings used as plasmafacing materials for today's tokamaks such as ASDEX Upgrade with the full-W wall and JET with the ITER-like wall (project JET-ILW) is known to differ from that of bulk tungsten [1822]. This is attributed to the different micro-structure and defect density. During the last decade, the research in the field of $\mathrm{W}$ coatings for fusion applications was mainly focused on the thermo-mechanical properties, particularly, on their resistance to high heat fluxes $\left(\mathrm{T}_{\max } \leq 2.000^{\circ} \mathrm{C}\right)[\mathbf{2 3}, 24]$. Dense nanostructured $\mathrm{W}$ coatings produced by Combined Magnetron Sputtering and Ion Implantation (CMSII) technology was chosen as a most promising coating for plasma-facing material application after successful high heat flux testing up to $10 \mathrm{MW} / \mathrm{m}^{2}$ in GLADIS facility [25]. But the information concerning the D retention for this type of coating is quite limited $[\mathbf{1 8 , 2 1 , 2 2 ]}$. In [21], the D retention in CMSII-W coatings on isotropic fine grain graphite (FGG) substrate was investigated for various incident ion energies ranging from 20 to $200 \mathrm{eV}$ per deuterium atom with fluences ranging from $1 \times 10^{23} \mathrm{~m}^{-2}$ to $2 \times 10^{25} \mathrm{~m}^{-2}$. It 
was shown that the D accumulation in CMSII-W coatings is higher compared to bulk PCW in all range of investigated temperatures from 320 to $650 \mathrm{~K}$. The D retention in nano-structured CMSII-W coating with a thickness of 7-10 $\mu \mathrm{m}$ was higher compared to other types of coatings, such as physical vapour deposited W coating with a thickness of 4-5 $\mu \mathrm{m}$ and plasma-sprayed W coating of $200 \mu \mathrm{m}$ for all investigated D irradiation conditions. It was suggested that the $\mathrm{D}$ retention correlates with the microstructure of $\mathrm{W}$ coatings. The high initial density of intrinsic defects in CMSII-W coating results in high D retention. The data of the D retention in CMSII-W coatings after exposure in ASDEX Upgrade reported recently in [18] are in a very good agreement with laboratory data reported in [21].

In future fusion power plants, PFMs will operate under a severe environment involving high heat flux, intensive irradiation and particle implantation (x-ray, gamma, neutrons, ions, neutrals and electrons). $14 \mathrm{MeV}$ neutrons generate radiation defects in the bulk of PFMs. Retention at radiation-induced defects in PCW can be a concern [11-13]. The effect of radiation damage on the $\mathrm{D}$ retention in nanostructured $\mathrm{W}$ coatings was investigated only in two papers $[\mathbf{2 2 , 2 6 ]}$. It was reported in $[\mathbf{2 2 , 2 6 ]}$ that the D concentration at radiation-induced defects produced by self-ion irradiation to a damage level of $\mathbf{3}$ displacements per atom (dpa) is the same for dense CMSII-W coatings and disordered coatings produced by Pulsed Laser Deposition (PLD) method and it is the same as in polycrystalline PCW. In other words, this implies that the density of radiation-induced defects is the same for all types of $\mathrm{W}$ coatings, regardless of the structure of each $\mathrm{W}$ material. On the other hand, if we define the radiation tolerance as the ratio of the density of initial intrinsic defects in un-irradiated material to the density of radiation-induced defects then the radiation tolerance increases with decreasing the grain size. In the paper [22], it was shown that CMSII-W coating exhibits enhanced radiation tolerance compared to PCW, namely, neutron irradiation will produce smaller change in 
coating properties compared to PCW. In the paper [26], it was shown that radiation-induced defects created by self-ion irradiation to a damage level of 3 dpa do not affect the D concentration in PLD-W films with crystallite size below $7 \mathrm{~nm}$. This implies that the formation of radiation-induced defects is suppressed in nanostructured W films with crystallite size below $7 \mathrm{~nm}$ because pre-existing nanoscaled boundaries behave as effective sinks for point defects, thus, enhancing defect annihilation and promote Frenkel pair recombination. This is in agreement with results reported in $[27,28,29]$ which demonstrated that materials based on nanoscale interfaces have improved radiation resistance.

It was also mentioned in [26] that despite the fact that nano-structured $\mathrm{W}$ films with small crystallite size possess a potential for improved radiation resistance compared to polycrystalline tungsten, the nano-structured $\mathrm{W}$ coatings have a high retention of hydrogen isotopes in comparison with PCW. Moreover, the build-up of D at the interface between coating and substrate can be a concern for both un-irradiated and neutron-irradiated materials [26] because it can cause hydrogen-induced cracking. However, PCW as a pure material has not been used so far for the entire first wall in fusion devices because of high cost implications to the project, its brittleness and bulkiness resulting in large structural weight. Therefore, tungsten coatings on a lighter substrate was found to be a good solution to investigate specific aspects concerning the compatibility of fusion plasma with a $\mathrm{W}$ wall. At the same time, the deposition of thick $\mathrm{W}$ coating on the structural material may be only one possible option to protect the structural material from interaction with the plasma.

The objective of the present work is to study in details the D retention in nano-structured W coatings exposed to D plasma in well-defined laboratory conditions in order to understand the fundamental retention mechanisms in those materials for fusion application. In contrast to tokamak devices, it is possible to control experimental parameters in plasma or ion beam 
irradiation experiments, for example, ion flux, fluence, ion energy and temperature of W specimen. By varying the deposition parameters, the controlled $\mathrm{W}$ film structure can be obtained even within the same deposition method. We will investigate dependences of the D retention in W coatings on (i) the substrate material, (ii) the nano-crystalline structure, (iii) the thickness of the coating and (iv) the presence of impurities in the coating. The D retention at the interface between the coating and the substrate is also studied.

\section{Experimental}

\subsection{Specimens}

W coatings used in the present study were prepared by:

1) combined magnetron-sputtering and ion implantation technique (CMSII-W) on FGG, CFC and Eurofer substrates (NILPRP Bucharest),

2) standard vacuum magnetron-sputtering (SMS-W) on FGG and Eurofer substrates (IPP, Garching),

3) pulsed laser deposition (PLD) method on FGG and Eurofer substrates (Politecnico di Milano).

FGG is isotropic fine grain graphite, CFC is carbon-fibre composite and Eurofer is reducedactivation ferritic/martensitic steel. Those C-based materials have been widely used as PFMs in various tokamaks in the last decades, and Eurofer steel is a candidate material for the structure material of future fusion reactors. The thickness of substrates was $1 \mathrm{~mm}$.

The deposition of CMSII-W coatings was done at National Institute for Laser, Plasma and Radiation Physics, Bucharest [23,24] in argon (Ar) atmosphere using a standard two axes rotation device with the rotation speed of $2 \mathrm{rot} / \mathrm{min}$. Typical parameters for the high voltage pulse discharge are: $\mathrm{U}=40 \mathrm{kV} ; \tau \approx 20 \mu$ s and $\mathrm{f}=25 \mathrm{~Hz}, \mathrm{U}_{\text {bias }}=-700 \mathrm{~V}$ for sputter cleaning 
between pulses and $-100 \mathrm{~V}$ for deposition, the argon flow rate is $25 \mathrm{sccm}$ and the deposition pressure is $0.8 \mathrm{~Pa}$. The temperature of the substrate during the deposition was about $300^{\circ} \mathrm{C}$. Such deposition method provides a nano-structure and high densification of the coating. The deposition of CMSII-W film on CFC substrates has been done for two fibre planes: pitch bundles oriented perpendicular and PAN bundles oriented parallel to the coated surface. The Ar content in the coating was detected by Rutherford backscattering spectrometry (RBS) to be $\sim 1 \%[26]$.

Some coatings were produced by runs with the oscillating jigging device. The difference in the coating conditions between the two systems is the following:

-With the oscillating jigging device, substrates remain all the time in front of the magnetrons. The deposition process is continuous. The deposition rate for $\mathrm{W}$ was about 1.4 $\mathrm{nm} / \mathrm{s}$.

-With the two axes rotation device (standard run), substrates rotate in front of the magnetrons. In this way they stay in front of the magnetron only half of the processing time. The other half of time the substrates do not see the magnetron targets. The deposition rate for W was about $0.7 \mathrm{~nm} / \mathrm{s}$. The deposition process is not continuous. In this case, the coating has bigger crystallite size.

The surface morphology of specimens was examined using a scanning electron microscope (SEM) equipped with a Focused Ion Beam (FIB) for in-situ cross sectioning. Fig. $\mathbf{1}$ shows the surface morphology of CMSII-W specimens on FGG produced by standard run (Fig. 1a) and run with the oscillating jigging device (Fig. 1b). The nanostructure of CMSII-W coating is clearly seen in Fig. 1. Transmission electron microscopy (TEM) analyses for CMSII-W coatings produced with oscillating device indicates the mean grain size less than 5$10 \mathrm{~nm}$ [24]. The CMSII-W coatings produced with standard run have bigger crystalline size 
compared to CMSII-W coatings produced with oscillating device as shown below (Table 1).

\begin{tabular}{|l|c|c|c|}
\hline \multicolumn{1}{|c|}{ Deposition technique } & $\begin{array}{c}\text { XRD W } \\
\text { peak }\end{array}$ & $\begin{array}{c}\text { Crystallite } \\
\text { domain size (nm) }\end{array}$ & $\begin{array}{c}\text { Density, } \\
\text { g/cm^3 }\end{array}$ \\
\hline CSMII-W/CFC (oscillating device) [24] & & $5-10$ & - \\
\hline CSMII-W/Eur (standard run) & 211 & $10-20$ & $\sim 19$ \\
\hline SMS-W/FGG (without Ar ion implantation) & 110 & 31 & $\sim 17$ \\
\hline SMS-W/FGG (with Ar ion implantation) & 110 & 19 & - \\
\hline SMS-W/Eur (without Ar ion implantation) & 110 & 43 & - \\
\hline c-PLDW/FGG & 110 & 7 & 18 \\
\hline a-PLDW/FGG & 110 & Amorphous $(\sim 2)$ & 11.5 \\
\hline
\end{tabular}

Table 1. Crystallite domain size of the different $\mathrm{W}$ coatings depending on deposition technique and substrate. Crystallite size has been estimated using Scherrer equation [32]. The same data for both coatings deposited on FGG and CFC using the same deposition parameters were obtained. Densities of several W coatings are also presented.

SMS-W films were prepared by a deposition using a commercial sputtering device (Discovery ${ }^{\circledR 18, ~ D e n t o n) ~ a t ~ I P P, ~ G a r c h i n g . ~ W i t h ~ t h e ~ a s s i s t a n c e ~ o f ~ a ~ l i q u i d ~} \mathrm{~N}_{2}$ cold trap, the deposition chamber was pumped down to a base pressure of less than $4.5 \times 10^{-5} \mathrm{~Pa}$. Deposition was performed in Ar atmosphere at 0.5 Pa. Prior to deposition the substrates were etched by Ar plasma at $-530 \mathrm{~V}$ bias for 2 minutes in order to clean the substrate surface. During the deposition a constant dc bias of $-360 \mathrm{~V}$ was applied to the substrate. At these settings the deposition rate of $\mathrm{W}$ was about $0.3 \mathrm{~nm} / \mathrm{s}$. Sample rotation during the deposition ensures the uniform coating thickness. The temperature of substrate under deposition was $\sim 100^{\circ} \mathrm{C}$. Two sets of depositions were performed. In the first set of experiments no extra substrate bias and heating or cooling was applied. In the second set of experiments extra substrate bias (-1250 V) was applied, which leads to the energetic Ar ion implantation during the deposition. Fig. 2 shows SEM images of SMS-W coatings with a thickness of $3 \mu \mathrm{m}$ produced on FGG with and 
without Ar ion implantation. The SMS-W coatings produced with Ar ion implantation has smaller grain size compared to the SMS-W coatings produced without Ar ion implantation as shown in Table 1. SMS-W coating shows 5-10\% lower density than PCW. Although both the CMSII-W and SMS-W coatings have a rather rough surface structure, the structure of SMSW coatings (see Fig. 2) is obviously different from the structure of CMSII-W coatings (see Fig. 1).

The difference between SMS and CMSII methods of deposition is that CMSII method involves a combination of magnetron sputtering and ion implantation. The periodical low energy ion bombardment (30-40 keV) of the layer during its growth in CMSII method can be seen as a Plasma Immersion Ion Implantation process where the plasma source is a magnetron discharge. The main improvement induced by ion bombardment in CMSII method on the coating performance is that low energy ion bombardment causes a high densification of the coating. Usually, films produced by SMS technique contain many vacancies and pores due to the limited surface mobility of the deposited atoms. Ion bombardment increases this mobility and displaces the atoms into nearby vacant site, therefore, the ion-assisted deposited coatings can achieve a density close to the bulk density [23,24]. At the same time the ion bombardment reduces the internal stress into the coating [23]. In the present work, in addition to usual SMS method, we apply extra substrate bias $(-1250 \mathrm{~V})$ to get Ar ion implantation during the SMS deposition. In the case of CMSII the dc bias is about -100 V. Moreover, the coating has been deposited at higher substrate temperature of $300 \mathrm{C}$ in the case of CMSII method compared to $100 \mathrm{C}$ in the case of SMS method.

In the PLD technique the source of energy that leads to the extraction of species from the target material is a nanosecond laser pulse. Because of the laser-matter interaction, a portion of the target is vaporized and expands towards the substrate. Exploiting the presence of a 
helium (He) atmosphere in the deposition chamber it is possible to finely tune the kinetic energy of the depositing species resulting in the deposition of compact $\mathrm{W}$ films with an amorphous-like crystalline structure.

Amorphous-like W films (a-PLDW) were produced by PLD, using the second harmonic of a Nd:YAG laser with wavelength $\lambda=532 \mathrm{~nm}$, repetition rate of $10 \mathrm{~Hz}$, pulse width of 7 ns and energy per pulse of $790 \mathrm{~mJ}$ as described in [30]. The laser with incident angle of 45 degrees is focused on a $\mathrm{W}$ target (with a diameter of $50.8 \mathrm{~mm}$ ) that is properly moved in order to ensure an uniform ablation. The spot area of the impinging laser on the target is about $9 \mathrm{~mm}^{2}$ and the laser fluence is about $8.8 \mathrm{~J} \mathrm{~cm}^{-2}$. The species ablated from the W target expand in the deposition chamber, where a He gas (purity 99.999\%) can be presented. The base pressure in the deposition chamber is $10^{-2} \mathrm{~Pa}$, and the He pressure is variable from the base pressure up to $75 \mathrm{~Pa}$. The expanding species, mainly single atoms in the chosen ablation regime, are collected on a substrate, FGG or Eurofer, positioned at $6 \mathrm{~cm}$ away from the target. The substrate is properly positioned and rotated in order to ensure the uniform deposition over an area $2.5 \mathrm{~cm}$ x $2.5 \mathrm{~cm}$. For the deposition of a-PLDW, He pressure was set at $75 \mathrm{~Pa}$ in the cases of the films deposited on FGG and silicon (Si) and it was set at $40 \mathrm{~Pa}$ in the case of the films deposited on Eurofer. The coating produced by this procedure has an amorphous-like structure (a-PLDW). A SEM picture of top view of the a-PLDW coating deposited on FGG is shown in Fig. 3a. In each substrate case, a thin W layer of 150 nm thickness was firstly deposited under the He base pressure of $10^{-2} \mathrm{~Pa}$. This provides a nano-crystalline W film, called columnar-W (c-PLDW), which was used as an interlayer between a-PLDW and the substrate with the aim of enhancing the adhesion of the coating and avoid delamination. Fig. 3b shows cross sectional SEM images of the multilayer system consisting of $1 \mu \mathrm{m}$ thick a-PLDW film and $150 \mathrm{~nm}$ thick c-PLDW film deposited on Si 
substrate as a reference. High magnification image of $150 \mathrm{~nm}$ c-PLDW film showing the columnar-like structure is presented in the inset of Fig. $\mathbf{3 b}$.

As it was measured by Energy Dispersive X-ray Spectroscopy (EDXS) in [30], the a-PLDW coating exhibits a high amount of stored oxygen, about 38\% of atomic concentration. As reported in [31], oxygen is physically adsorbed in the intergranular volume in the aPLDW during the deposition process because oxygen is present as an impurity in the background gas. The formation of tungsten oxide was not found [31].

The texture of coatings was examined by X-ray diffraction (XRD). The XRD diagram of the a-PLDW/c-PLDW sandwich coating deposited on FGG is shown in Fig. 4 in comparison with bare FGG. In the diffraction pattern of the coated sample (top of Fig. 4), besides the peaks related to the graphite substrate, it is possible to appreciate a strong reflection at $40.07^{\circ}$ that is related to the 110 reflection of alpha-W; the downshift of $2 \theta$ by $0.2^{\circ}$ respectively to the usual position $\left(40.27^{\circ}\right)$ is probably related to the presence of internal stresses in the film. In addition a broad band centered at about $39.02^{\circ}$ is also present. The (110) reflection comes from the c-PLDW adhesion layer that exhibits a nanocrystalline structure with the crystallite size of about $7 \mathrm{~nm}$ estimated using the Scherrer formula [32]. The broad band is instead related to the amorphous a-PLDW coating with corresponding crystallite domain size being about $2 \mathrm{~nm}$ in agreement with previous findings [30].

c-PLDW and a-PLDW films on FGG substrate have a preferred orientation of (110) planes perpendicular to the surface. This means that PLD films preferentially grow following the direction where the crystalline plains exhibit the higher density of atoms, namely (110) in the case of W. The nano-sized grains of CMSII-W deposited on CFC substrate with oscillating device possess a preferred orientation of (200) planes parallel to the surface and (110) planes perpendicular to the surface as it was reported in [24]. CMSII-W coatings 
deposited on Eurofer substrate with standard run have a fibre-like texture with preferential grain orientation in directions of (211) planes parallel to the surface as shown in Fig. 5. Fig. 5 shows XRD diffraction pattern of CMSII-W film deposited on Eurofer using standard run and SMS-W coatings deposited on Eurofer and FGG with and without Ar ion implantation. As in the case of CMSII-W films, SMS-W coatings have a fibre-like texture but the texture depends on the deposition parameters. SMS-W coatings deposited on FGG and Eurofer substrates without Ar ion implantation have grains with preferential orientation of (110) and SMS-W coatings deposited on FGG with Ar ion implantation have grains with preferential orientation of (200). It is interesting to mention that although FGG substrate does not have preferential orientation, W coatings on FGG have preferential orientation which depends on the deposition parameters. This indicates that deposition does not lead to an epitaxial film growth on the substrate material (in this case, crystallographic orientation is determined by the crystallographic orientation of the substrate), but the coatings grow with a particular crystallographic orientation depending on the energy of the impinging species. For example, the W coatings have a preferential crystallographic orientation of (200) or (211) using Ar ion implantation, but they have the preferential crystallographic orientation of (110) without $\mathrm{Ar}$ ion implantation (see Fig. 5).

The mean crystallite size estimated from the XRD data using the Scherrer formula [32] for different W coatings are collected in Table 1. Although Scherrer formula gives only an estimation of crystallite size and has to be intended as a lower limit of the crystallinity, nevertheless the comparison among the presented samples is possible because the same procedure of fitting was used.

\subsection{Plasma exposure and post-mortem analysis}


Samples were exposed to deuterium plasma generated by a well quantified electroncyclotron resonance (ECR) plasma source in the experiment PLAQ which delivers mostly $\mathrm{D}_{3}{ }^{+}$ (97\%) ions [33]. A dc bias of $-60 \mathrm{~V}$ was applied to the substrate holder to accelerate the ions in the sheath leading to an energy of about $60 \mathrm{eV}$ per $\mathrm{D}_{3}{ }^{+}$that corresponds to a mean energy of about $20 \mathrm{eV}$ per deuteron. In general, there is a plasma potential of several volts but we do not take it into account because its insignificant contribution. The ion flux was about $10^{20} \mathrm{D} / \mathrm{m}^{2} \mathrm{~s}$. The D plasma exposure was performed to a fluence of $2.2 \times 10^{25} \mathrm{D} / \mathrm{m}^{2}$. In the majority of experiments, the sample temperature was $600 \mathrm{~K}$ during the plasma exposure to eliminate the effect of D trapping by dislocations which plays a dominant role in the D retention in PCW at lower temperatures [2-4]. In some experiments, the plasma exposure was performed at sample temperature of 370 or $700 \mathrm{~K}$.

After D plasma exposure, the D depth profile was measured by Nuclear Reaction Analysis (NRA) using ${ }^{3} \mathrm{He}^{+}$as the analysing beam. In order to determine the quantitative D depth profile, the ${ }^{3} \mathrm{He}^{+}$incident energy was varied from 0.69 to $4.0 \mathrm{MeV}$, which allows measuring the $\mathrm{D}$ depth profile up to a depth of about $6 \mu \mathrm{m}$. The protons emitted by $\mathrm{D}\left({ }^{3} \mathrm{He}\right.$, p) ${ }^{4}$ He nuclear reaction were detected, and the D concentration profile was then determined by using SIMNRA to fit its calculated proton spectrum to the experimental one. Details can be found elsewhere [34]. The total amount of retained D in those materials was determined by thermal desorption spectroscopy (TDS) [35]. The samples were heated resistively up to $1500 \mathrm{~K}$ with a linear ramp of $2 \mathrm{~K} / \mathrm{s}$. The samples were stored at vacuum between measurements.

\section{Results and discussion}

\subsection{Dependence of the $D$ retention in coatings on substrate material}


In the case of CMSII-W coatings with a thickness of $10 \mu \mathrm{m}$, the coatings were produced by standard run with molybdenum (Mo) interlayer between coating itself and substrate. Fig. 6a shows the cross sectional SEM image of CMSII-W coating of 10-12 $\mu \mathrm{m}$ on Eurofer substrate with Mo interlayer with a thickness of $3 \mu \mathrm{m}$. The Mo was selected and successfully used as an interlayer between W and CFC and between W and Eurofer. Both Mo and W are deposited by CMSII technique sequentially, but in the same deposition cycle. Details about the deposition process are given elsewhere [36]. The beneficial role of Mo is connected with the adjustment of the thermal expansion mismatch between $\mathrm{W}$ and substrate $\left(\alpha \mathrm{W}=4-5 \times 10^{-6} \mathrm{~K}^{-1} ; \alpha \mathrm{CFC}=10\right.$ $12 \times 10^{-6} \mathrm{~K}^{-1}$ perpendicular to fiber and $0-1 \times 10^{-6} \mathrm{~K}^{-1}$ parallel to fiber plane; $\alpha$ Eurofer=10$\left.12 \times 10^{-6} \mathrm{~K}^{-1} ; \alpha \mathrm{Mo}=7.2 \times 10^{-6} \mathrm{~K}^{-1}\right)$. It contributes to prevent the delaminating of the layer and to enhance the thermal fatigue resistance under the fusion-relevant high heat flux conditions. The influence of the Mo interlayer and the high voltage pulse discharge on the internal stress and the performances of the $\mathrm{W}$ coatings was investigated in details in the paper [23].

To define a role of the Mo interlayer on the D retention, we produced and used coatings with and without the Mo interlayer. Fig. 6b shows the cross sectional SEM image of SMS-W coating with a thickness of $3 \mu \mathrm{m}$ deposited directly on Eurofer substrate.

Fig. 7 shows examples of D depth profiles in CMSII-W coatings with a thickness of $10 \mu \mathrm{m}$ on different substrates after the D plasma exposure at $600 \mathrm{~K}$. The $\mathrm{D}$ depth profiles reveal that the highest $\mathrm{D}$ concentration is in the $\mathrm{W}$ films deposited on Eurofer. The D concentration is very similar in CMSII-W coatings deposited on CFC with different orientations of PAN and pitch fibres, either parallel or perpendicular to the plasma-facing surface. The D concentration in coatings on different substrates differs by a factor of 1.5 that is within experimental errors. The D concentration in CMSII-W coatings after exposure to the D plasma at $600 \mathrm{~K}$ is quasi- 
homogeneous throughout the NRA detectable range (up to $\sim 6 \mu \mathrm{m}$ in depth) and reaches 0.20.4 at. $\%$.

For comparison, D depth profiles in two types of PCW specimens are also shown in Fig. 7. The specimen labeled as WI is a tungsten material fulfilling the European ITER-grade specification (produced by Plansee AG). The grains of WI are preferentially elongated to be normal to the irradiated surface, and the mean grain size is around 5-30 $\mu \mathrm{m}$. Recrystallized tungsten, WR, has bigger grains up to $50-100 \mu \mathrm{m}$ [11]. Subgrains within one grain of the mean size of $1-3 \mu \mathrm{m}$ in WI and $\sim 10 \mu \mathrm{m}$ in WR were measured by TEM. NRA data for WI and WR were taken from [26]. Both PCW specimens demonstrate the thin D-rich layer at the surface up to $0.5 \mu \mathrm{m}$ with $\mathrm{D}$ concentration ranged between $0.5-1$ at.\% which can be attributed to the presence of both (i) initial natural defects near the surface and (ii) ion-induced defects as it was proposed in early papers [2-4]. D concentrations in the bulk of WR and WI are 2x103 and $6 \times 10^{-3}$ at.\%., respectively. This means that the $\mathrm{D}$ concentration varies $2-3$ times depending on the PCW grades that is in agreement with [5]. The D concentration in the bulk of PCW is about two orders of magnitude lower than in CMSII-W coating (Fig. 7).

Total D retention more significantly depends on the substrate material than the $\mathrm{D}$ concentration in a coating because $\mathrm{D}$ can penetrate into the substrate material and, thus, the $\mathrm{D}$ retention in the substrate contributes to the total D retention: Ret_total $=$ Ret_coating + Ret_substrate. Fig. 8 shows thermal desorption spectra (TDS) of D from CMSII-W coating with a thickness of $10 \mu \mathrm{m}$ on different substrates after exposure to the D plasma at $600 \mathrm{~K}$ with ion energy of $20 \mathrm{eV}$ per $\mathrm{D}$ up to a fluence of $2.2 \times 10^{25} \mathrm{D} / \mathrm{m}^{2}$. The $\mathrm{W}$ coating deposited on Eurofer by CMSII technique shows the highest D retention. The D retention in CMSII-W coating deposited on Eurofer is two times higher than that deposited on C-based substrates. 
This is because the total D retention in coatings on different substrates depends also on the D penetration and retention in substrate itself: the D retention is higher in CMSII-W coating on Eurofer substrate because of the highest diffusion coefficient of D in Eurofer [37] than in Cbased materials, resulting in more significant contribution of the D retention in the Eurofer substrate in the total retention.

TDS of D from CMSII-W film on the Eurofer substrate has one very board peak with maximum of about $\mathbf{8 7 0} \mathbf{K}$. The broad shape of the TDS peak indicates the presence of a spectrum distribution of defects with similar binding energy for D. The TDS peak can be fitted by two Gaussian peaks of $\sim \mathbf{8 1 0}$ and $\sim 920$ K (dashed line in Fig. 8).

It is possible to resolve two main TDS peaks of $\sim \mathbf{8 2 0}$ and $\sim \mathbf{9 3 0} \mathbf{K}$ from coatings deposited on C-based substrate that are similar to two Gaussian peaks of $\sim \mathbf{8 1 0}$ and $\sim \mathbf{9 2 0} \mathbf{K}$ in the case of CMSII-W film on the Eurofer substrate. An additional third high-temperature peak of 1270-1290 K in the case of CMSII-W film on C-based substrates with much smaller amplitude can be attributed to D trapped by carbon because this TDS peak is absent in the case of W coating on the Eurofer substrate.

TDS of D from polycrystalline W ITER grade, WI, and from bare Eurofer are also shown in Fig. 8 for comparison. The thickness of those reference bulk samples was 0.5-1 mm. TDS has a single broad peak with a maximum of about $850 \mathbf{K}$ in the case of WI. TDS has two peaks of $\sim \mathbf{8 7 0}$ and $\sim \mathbf{1 0 0 0} \mathbf{K}$ in the case of bare Eurofer. The absence of the high-temperature peak of $\sim 1270-1290 \mathrm{~K}$ in the case of WI and in the case of the CMSII-W coating on Eurofer substrate confirms our suggestion that this peak is associated with D which was chemically bounded with carbon.

The D concentration in CMSII-W coatings is homogeneously distributed over all coating thickness up to $6 \mu \mathrm{m}$ (Fig. 7). Since the thickness of CMSII-W coating is higher than the 
maximal depth of the present NRA measurements, we cannot observe the D concentration at an interface between the coating and the substrate. An increase of D concentrations at the interface between the coating and the substrate can be easily observed in the cases of coatings with the thickness of $3 \mu \mathrm{m}$. Fig. 9 shows an example of the D concentration in CMSII-W coatings with the thickness of $3 \mu \mathrm{m}$ deposited on the Eurofer substrate with and without Mo interlayer. In this case, the NRA detectable range covers the interlayer and the interface region. The D concentration at the interface between the CMSII-W coating and the substrate is about one order of magnitude higher than that in the coating itself, and decreases from about 3 at.\% at the interface down to $\sim(1-2) \times 10^{-2}$ at.\% at the depth of $6.5 \mu \mathrm{m}$ within Eurofer substrate. The D concentration is identical in CMSII-W coatings with and without Mo interlayer. But the D concentration in Mo interlayer in the case of CMSII-W coating with Mo interlayer is higher compared to the D concentration in the case of CMSII-W coating deposited on bare Eurofer without Mo interlayer due to higher D concentration in Mo compared to Eurofer [16,26,37].

One CMSII-W coating with Mo interlayer was heated up to $1000 \mathrm{~K}$ using TDS set-up and hold for 10 minutes at $1000 \mathrm{~K}$ prior to the $\mathrm{D}$ plasma exposure. The pre-annealing of the CMSII-W coating with the Mo interlayer at $1000 \mathrm{~K}$ for 10 minutes leads to a sufficient reduction of the $\mathrm{D}$ concentration in the Mo interlayer but it is still higher than in the Eurofer substrate (Fig. 9). At the same time, the D concentration slightly (by 1.5 times) increases in the coating itself after pre-annealing, either due to slight change in the microstructure of the coating after such pre-annealing or due to slight difference in the microstructure of both coatings directly after production.

TDS of D from CMSII-W coatings with a thickness of $3 \mu \mathrm{m}$ deposited on Eurofer substrate with and without Mo interlayer is shown in Fig. 10. The total D retention is very 
similar in both types of coatings. This indicates that, although the $\mathrm{D}$ concentration is increased locally in the interlayer, it still makes minor contribution to the total retention. TDS from CMSII-W coating with a thickness of $10 \mu \mathrm{m}$ deposited on Eurofer with Mo interlayer is shown in Fig. 10 for comparison. The higher thickness of the coating leads to broader TDS peak shifted in the high temperature range because of release of $\mathrm{D}$ from deeper layers.

Another example of an influence of pre-annealing at $1000 \mathrm{~K}$ for 10 minutes prior to the plasma exposure on the D concentration in the CMSII-W coating with a thickness of $10 \mu \mathrm{m}$ deposited on Eurofer with Mo interlayer is shown in Fig. 11. In this case, pre-annealing leads to a reduction of the $\mathrm{D}$ concentration in the coating by a factor of $\sim 2-3$. The $\mathrm{D}$ retention calculated from the depth profile measurements by integrating the $\mathrm{D}$ concentration over the depth up to $6.5 \mu \mathrm{m}$ in un-annealed CMSII-W coating is 2.35 times higher than in preannealed CMSII-W coating. Total D retention obtained from TDS measurements by integrating the D desorption rate over the time for un-annealed multilayer material CMSIIW/Mo/Eurofer is 5 times higher in comparison with pre-annealed CMSII-W/Mo/Eurofer coating as shown in Fig. 12. A more pronounced reduction of the total D retention in preannealed CMSII-W/Mo/Eurofer sample compared to the reduction of the D concentration in un-annealed CMSII-W/Mo/Eurofer sample can be connected with a significant reduction of D in Eurofer material after pre-annealing (see Fig. 9). Fig. 13 shows a significant decrease of the D concentration in Eurofer after pre-annealing at $1200 \mathrm{~K}$.

Therefore, pre-annealing can result either in a slight increase of the D concentration in CMSII-W coating (Fig. 9) or in a reduction of the D concentration in the coating (Fig. 11). The reason that annealing causes slightly higher D retention in some cases, and slightly lower D retention in CMSII-W coating in other cases, is unclear. Actually, such slight increase or decrease of the D concentration in CMSII-W coating can be due to a slight difference in the 
microstructure of coatings directly after manufacturing. Total D retention defined from TDS by integrating of the D desorption rate from a CMSII coating on Eurofer substrate over the time was lower in pre-annealed coating compared to un-annealed one that is mainly connected with a reduction of the $\mathrm{D}$ retention in substrate material after pre-annealing (see Fig. 13).

The structure of the coatings produced on the same or the different substrates is also not identical that leads to variation in the $\mathrm{D}$ concentration in coatings by a factor of less than 2 . If the D concentration in CMSII-W coating on Eurofer was highest compared to the D concentration in CMSII-W coating on C-based substrate in the case of exposure of samples to the D plasma at $600 \mathrm{~K}$ (fig. 7), the D concentration in CMSII-W coating on Eurofer was lowest compared to the D concentration in CMSII-W coating on C-based materials in the case of exposure of samples to the D plasma at $370 \mathrm{~K}$ (Fig. 14).

\subsection{Dependence of the $D$ retention on nano-crystalline structure of coatings}

3.2.1 Influence of the deposition technique on the nano-structure of coatings and the D retention

In contrast to the minor dependence of the $\mathrm{D}$ concentration in the coating on the substrate material, the D concentration is strongly dependent on nano-crystalline coating structure, which in turn depends on the method of production and deposition parameters within the method.

Fig. 14 shows D depth profiles in CMSII-W coatings with different thicknesses on Eurofer and C-based substrates. All coatings were produced with Mo interlayer. SEM pictures of the different structure of coatings deposited with the oscillating jigging device and standard run are shown on the right side. As mentioned above, the D concentration in CMSII-W coatings 
with a thickness of $10 \mu \mathrm{m}$ is quasi-homogeneously distributed over coating thickness at least up to $6.5 \mu \mathrm{m}$. On the other hand, there is a quantitatively systematic difference among those CMSII-W coatings, i.e. the D concentration in coatings produced with oscillating jigging device (three upper curves in Fig. 14) is 2 at.\%, whereas the D concentration in coatings produced with standard run (four bottom curves in Fig. 14) is $\sim 0.6$ at.\% after the D plasma exposure at $370 \mathrm{~K}$. The D concentration in CMSII-W coatings with a thickness of $3.5 \mu \mathrm{m}$ has two maximums of $~ 8$ at.\% on depths of 3.5 and $5.5 \mu \mathrm{m}$ which correspond to the $\mathrm{D}$ concentration at interlayers between CMSII-W film and Mo and between Mo and Eurofer, respectively. The grain size of CMSII-W coating deposited with oscillating jigging device is smaller than the grain size of CMSII-W coating deposited with standard run (Table 1). The question is, if the difference in the $\mathrm{D}$ concentration by a factor of three is due to the difference in the Ar concentration or the grain size of the coatings produced with different deposition parameters (see section 3.2.2 below).

A comparison of $\mathrm{D}$ concentration profiles in $\mathrm{W}$ coatings with a thickness of $\sim 3 \mu \mathrm{m}$ produced by different methods on Eurofer substrate is shown in Fig. 15. The highest D concentration is in disordered a-PLDW coating followed by CMSII-W coating. The D concentration in SMS-W coatings is noticeably less compared to a-PLDW and CMSII-W coatings. This clearly shows that the $\mathrm{D}$ retention in a $\mathrm{W}$ coating strongly depends on the fabrication method in contrast to minor dependence on the substrate.

In spite that the D concentration in a-PLDW coating is higher than in CMSII-W coating, the total D retention in CMSII-W/Eurofer is higher. TDS of D from the same W coatings as in Fig. 15 with a thickness of $3 \mu \mathrm{m}$ produced by different methods on the Eurofer substrate after the D plasma exposure with $20 \mathrm{eV}$ at $600 \mathrm{~K}$ is shown in Fig. 16. It can be two reasons of 
higher D retention in CMSII-W coating than in a-PLDW coating. The first reason can be connected with the enhanced deuterium desorption from a-PLDW coating because of amorphous-like structure of this coating providing open porosity. The second reason is that the high density of defects in a-PLDW coating mitigates the D diffusion into the bulk. As shown in [13], the time to saturate defects with D up to a depth $x$ increases with increasing the density of defects. Because of the higher density of defects in a-PLDW coating, the present fluence was not enough to saturate defects with $\mathrm{D}$ in the entire thickness (up to $\sim 3 \mu \mathrm{m}$ in depth) of a-PLDW coating. On the other hand, the quasi-homogeneous D profile throughout the coating thickness suggests that all available trapping sites in CMSII-W coating are saturated with D. Furthermore, the high D concentration at the interface between the CMSIIW coating and the Eurofer substrate is observed, which can also contribute to the higher total D retention in CMSII-W coating compared to a-PLDW coating.

To see a comparison of desorption peaks from different coatings on Eurofer substrate and bulk tungsten, normalized TDS data are shown in Fig. 17. The first two peaks at $\sim \mathbf{8 0 0} \mathbf{~ K}$ and $\sim 900 \mathbf{K}$ are commonly observed in a-PLD-W, SMS-W and CMSII-W, indicating that the dominant defects for D are the same in all types of coatings. Nevertheless, the density of defects can be varied depending on the method of production. The dominant TDS peak can be slightly shifted in low-temperature range (as for a-PLDW and SMS-W films) or slightly shifted in high-temperature range (as for CMSII-W film) compared to polycrystalline WI. The a-PLDW and SMS-W coatings have an additional third peaks at $1060 \mathrm{~K}$. Table 2 shows main TDS peaks from different types of coating.

\begin{tabular}{|l|l|l|l|l|}
\hline Material & \multicolumn{3}{|c|}{ TDS peaks (K) } \\
\hline Eur & 870 & & 1000 & \\
\hline WI & 850 & & & \\
\hline $10 \mu \mathrm{m} \mathrm{CMSII-W/Mo/Eur}$ & $\begin{array}{l}870 \\
(820 \text { Gauss })\end{array}$ & (920 Gauss) & & \\
\hline
\end{tabular}




\begin{tabular}{|l|l|l|l|l|}
\hline $\begin{array}{l}10 \mu \mathrm{m} \text { CMSII- } \\
\text { W/Mo/FGG }\end{array}$ & 820 & 930 & & $1270-1290$ \\
\hline $3 \mu \mathrm{m}$ CMSII-W/Eur & 800 & 890 & & \\
\hline $\begin{array}{l}3 \mu \mathrm{m} \text { SMS-W/Eur } \\
\text { without extra bias }\end{array}$ & 790 & & 1040 & \\
\hline $3 \mu \mathrm{m}$ a-PLDW/Eur & 790 & 890 & 1060 & 1290 \\
\hline $\begin{array}{l}3 \mu \mathrm{m} \text { SMS-W/FGG } \\
\text { without extra bias }\end{array}$ & 800 & 930 & & 1290 \\
\hline $\begin{array}{l}3 \mu \mathrm{m} \text { SMS-W/FGG } \\
\text { with extra bias }\end{array}$ & 790 & 930 & & 1290 \\
\hline 150 nm c-PLDW/FGG & 790 & 930 & & 1290 \\
\hline $1 \mu \mathrm{m}$ a-PLDW/FGG & 760 & 930 & & \\
\hline
\end{tabular}

Table 2. TDS peaks (in Kelvin) from different $\mathrm{W}$ coatings in comparison with Eurofer (indicated as Eur) and W ITER grade (indicated as WI), after the D plasma exposure with 20 $\mathrm{eV}$ to a fluence of $2.2 \times 10^{25} \mathrm{D} / \mathrm{m}^{2}$ at $600 \mathrm{~K}$.

As another example of TDS from coatings with different micro- and nano- structure, a comparison of the D desorption behaviour from c-PLDW and a-PLDW/c-PLDW multilayer coatings on FGG substrate is shown in Fig. 18. TDS from c-PLDW coating with a thickness of $150 \mathrm{~nm}$ has three dominant peaks, at $\sim \mathbf{7 9 0 , ~} \sim \mathbf{9 3 0}$, and $\sim \mathbf{1 2 9 0} \mathbf{K}$. All peak temperatures are similar to dominant TDS peaks in cases of CMSII-W and SMS-W films (Table 2). The hightemperature peak of $\sim 1290 \mathrm{~K}$ indicates the trapping of D by carbon as observed in CMSII-W coatings on FGG discussed above (see Fig. 8). Deposition of an additional $1 \mu \mathrm{m}$ of a-PLDW coating on the existing $150 \mathrm{~nm}$ of c-PLDW coating increases the D retention by a factor of two. The comparison of desorption spectra shows an increase of the lower temperature desorption peak in the a-PLDW/c-PLDW multilayer coating, indicating an increase of intrinsic defect density in amorphous-like coating. One of the main TDS peaks of $790 \mathrm{~K}$ in cPLDW coating is shifted in the low-temperature range for a-PLDW coating to be at $760 \mathrm{~K}$ instead of $790 \mathrm{~K}$ as for c-PLDW coating (Fig. 18). This reveals the high density of trapping sites with lower binding energies for D in a-PLDW coating with smaller grain size (2 nm) 
compared to c-PLDW coating with bigger grain size $(\mathbf{7} \mathbf{~ n m})$. In general, the nanostructures are more disordered with decreasing the crystallite size. The lower crystallite size of the amorphous-like coating results in the higher $\mathrm{D}$ retention with lower trapping energies compared to columnar-like coating with bigger crystallite size. Moreover, the density of aPLDW coating is $\sim 60 \%$ less than the density of PCW and CMSII-W coating [26] indicating high porosity of a-PLDW coating which may lead to an increase in the D retention by trapping in the pores.

Regarding TDS peaks of $\sim 790$ and $~ 930 \mathrm{~K}$, we do not have accurate information about specific types of defects that capture D. We can only speculate that TDS peaks of $\sim 790 \mathrm{~K}$ and 930 K correspond to D trapped at vacancy clusters of different sizes attached to the grain boundaries as it was postulated in [26]. Probably, the shift of one of the main TDS peaks in cPLDW coating in the low-temperature range for a-PLDW coating is a result of the multiple trapping of $\mathrm{D}$ in a pore. However, we cannot identify accurately the corresponding trapping sites without detailed TEM and PALS analysis combined with modelling.

\subsubsection{Influence of Ar on the nano-structure of coatings and the D retention}

Ar is widely used as working gas in various sputter deposition techniques, and a certain amount of Ar can be incorporated in the coating during the deposition process. In JET-ILW, unexpected Ar signal was observed during the plasma discharge, which is attributed to the thermal release of Ar from CMSII-W coating tiles [38]. Influence of Ar impurity on the D retention in $\mathrm{W}$ coatings is an issue to be clarified, especially because it is impossible to produce coatings with different microstructure by magnetron sputtering without some change of the Ar concentration in samples. Therefore, it is important to study both effects of the grain size and the Ar concentration on the $\mathrm{D}$ retention to define the dominant factor govern the $\mathrm{D}$ 
retention in the coating. In this study, the initial Ar concentration was measured by RBS. The Ar retention in samples during pre-annealing prior to the plasma exposure and after the D plasma exposure was measured by TDS up to $1400 \mathrm{~K}$.

The Ar concentration in CMSII-W coatings deposited with oscillating jigging device was lower or similar to that in CMSII-W coatings deposited with standard run. This suggests that the presence of $\mathrm{Ar}$ is not a major reason for the increase of the $\mathrm{D}$ retention in CMSII-W coatings deposited with oscillating jigging device (see Fig. 14). As mentioned in the previous section, some CMSII-W coatings with Mo interlayer were annealed at $1000 \mathrm{~K}$ for 10 minutes prior to the D plasma exposure. During the pre-annealing, the Ar thermal desorption spectra were measured too. It was found that the Ar retention in both CMSII-W coatings with thicknesses of $10 \mu \mathrm{m}$ and $3 \mu \mathrm{m}$ was decreased by about $20 \%$. However, the D retention did not show systematic change, i.e., the $\mathrm{D}$ concentration in $3 \mu \mathrm{m}$ thick coating was slightly increased whereas the $\mathrm{D}$ concentration in $10 \mu \mathrm{m}$ thick coating was decreased after preannealing. Therefore, the D concentration in CMSII-W coating does not correlate with a reduction of the Ar concentration in the coating.

Another difference is the grain structure as it was mentioned in the previous section, i.e., coatings produced with oscillating jigging device have smaller grain size compared to coatings produced with standard run. The change from bigger to smaller crystallite size could be responsible for an enhancement of the $\mathrm{D}$ retention in the coating, rather than the presence of Ar. This trend is consistent with the result observed in PLDW coatings: the D concentration increases with decreasing the crystallite size [26]. As the grain size decreases, there is a significant increase in the volume fraction of grain boundaries or interfaces which strongly influence the D retention. As reported in [26], an increase in the grain boundaries can 
lead to an increase in vacancy clusters/nanopores attached to the grain boundaries that effectively trap D.

To clarify whether the presence of Ar in coatings can be a dominant factor for the D retention, SMS-W coatings were deposited without and with extra applied bias to the substrate, consequently, without and with energetic Ar ion implantation. Fig. 19 shows TDS of Ar from SMS-W coatings deposited with and without the extra substrate bias voltage. Although there is a scatter of the data, the Ar retention in samples deposited with the extra bias is about 2-5 times higher than that without the extra bias. This indicates that the substrate bias enhanced the Ar retention in the coating by inducing the energetic Ar ion implantation. As one can see from Fig. 19, only part of Ar is desorbed from SMS-W samples even at temperatures up to $1400 \mathrm{~K}$. In the case of SMS-W coating without Ar ion implantation, TDS has main Ar peaks of 600, 800 and 1200-1300 K. In the case of SMS-W coating with Ar ion implantation, TDS has three main peaks of 800,1100 and $\geq 1300 \mathrm{~K}$, and the largest desorption peak appeared at temperature of $\geq 1300 \mathrm{~K}$.

Fig. 20 shows D depth profiles in SMS-W coatings with a thickness of $\sim 3 \mu \mathrm{m}$ on a) FGG and b) Eurofer with and without Ar ion implantation during the deposition. Without Ar ion implantation, the D concentration taking on a depth of $1.3 \mu \mathrm{m}$ is about 0.05 at.\% in SMS-W coating on Eurofer substrate and about 0.025 at.\% in SMS-W coating on FGG substrate. The substrate material has not significant effect on the D concentration in SMS-W coatings similar to the case of CMSII-W coatings. In the case of SMS-W coatings deposited with extra bias, the D concentration taking on a depth of $1.3 \mu \mathrm{m}$ is about 0.15 at.\% in both SMS-W coatings on Eurofer and FGG substrates. Therefore, the D concentration in SMS-W coating produced with extra bias is 3-5 times higher than that without the extra bias, indicating the formation of additional defects in the coating deposited with extra bias. 
A comparison of TDS from SMS-W coatings with various deposition conditions is shown in Fig. 21. The coating deposited on FGG material shows slightly higher D retention than that deposited on Eurofer substrate. Both SMS-W coatings on FGG with and without the extra bias have two main TDS peaks at $\sim \mathbf{8 0 0}$ and $\sim \mathbf{9 3 0} \mathbf{K}$ which are similar to TDS peaks observed in other coatings (Figs. 8,16,18). On the other hand, the total D retention is much higher in the case of coatings produced with smaller grain size (with Ar ion implantation) by a factor of $\sim 5$. This means that although the trapping sites for $\mathrm{D}$ are essentially identical for both SMS-W coatings with and without additional bias, the density of trapping sites is different. In the case of SMS-W coating produced with smaller grain size (with extra bias), the dominant TDS peak of $800 \mathbf{K}$ is slightly (by $20 \mathrm{~K}$ ) shifted in low-temperature range, indicating the presence of high density of defects with slightly smaller binding energies for D than in the case of SMSW coating produced with bigger grain size (without extra bias). The same tendency was observed in Fig. 18 for the PLDW films: a-PLDW coating with smaller grain size (2 nm) has high density of trapping sites with smaller binding energies for D compared to c-PLDW coating with bigger grain size $(7 \mathrm{~nm})$. The third TDS peak of $\sim 1290 \mathrm{~K}$ for SMS-W coatings on FGG substrate shown in Fig. 21 indicates the strong trapping of D by carbon that is similar to all coatings on FGG substrate (CMSII-W in Fig. Fig. 8 and PLDW in Fig. 18).

In addition to increasing the concentration of argon, applying the extra bias also induced the smaller crystallite size as observed in the SEM examination shown on the right side of Fig. 20a and confirmed by XRD (see Table 1). Although in the case of CMSII-W coating, it was shown that the $\mathrm{D}$ retention in the coating does not correlate with a reduction of the $\mathrm{Ar}$ concentration in the coating but correlate with increasing the mean grain size, we would like to clarify if the difference in the D retention in SMS-W coatings produced with and without extra bias is due to the difference in the Ar concentration or the grain size. For this reason, 
one of the SMS-W coatings deposited on FGG with Ar ion implantation was annealed at 1273 $\mathrm{K}$ for 10 minutes prior to the $\mathrm{D}$ plasma exposure. This pre-annealing results in a reduction of the Ar retention by $20 \%$, being roughly comparable Ar retention amount in SMS-W coating without the extra bias. But the D retention was decreased only by a factor of 1.3 (Fig. 21), and it is still much higher than the D retention in SMS-W coating without the extra bias. This suggests again that the presence of Ar in SMS-W coating plays a minor role for the D retention as with CMSII-W coatings. On the other hand, the SMS-W coatings deposited with Ar ion implantation have smaller grain size $(\mathbf{1 9} \mathbf{~ n m})$ compared to SMS-W coatings deposited without Ar ion implantation (31-43 $\mathbf{~ m})$ as shown in Table 1. This indicates that the smaller grain size results in the higher $\mathrm{D}$ concentration as obtained in other coatings.

\subsection{The $D$ retention at the interface between the coating and the substrate}

D concentrations in SMS-W coatings without Ar ion implantation are slightly higher at the interface between the coating and the substrate than in coatings itself, and decrease from about 0.05 at.\% and 0.08 at.\% at the interface (at a depth of $3 \mu \mathrm{m}$ ) down to less than $\sim 1 \times 10^{-2}$ at.\% and $\sim 1 \times 10^{-3}$ at.\% at the depth of $6 \mu \mathrm{m}$ inside FGG (Fig. 20a) and Eurofer (Fig. 20b) substrates, respectively. D concentrations in SMS-W coatings deposited with Ar ion implantation are strongly higher at the interface between the coating and the substrate, and decrease from about 0.4 at.\% at the interface down to less than $\sim 2 \times 10^{-2}$ at. $\%$ and $\sim 2 \times 10^{-3}$ at.\% at the depth of $6 \mu \mathrm{m}$ inside FGG (Fig. 20a) and Eurofer (Fig. 20b) substrates, respectively. Such maximum of the D concentration at the interface between the coating and the substrate was also observed in the case of CMSII-W films (Figs. 9,15) and physical vapour deposited tungsten (PVD-W) with a thickness of 4-5 $\mu \mathrm{m}$ in [21] and associated with the D retention at 
defects produced by coating fabrication. It is reasonable to suggest that Ar ions striking the substrate during the deposition process lead to a formation of nano-pores at the interface, thus, increasing the inventory of $\mathrm{D}$ at the interface. Furthermore, any cracks and pores in the interlayer between materials result in the enhanced $\mathrm{D}$ inventory which can lead to embrittlement and even coating delamination. This means that the D retention at interlayers can be a concern.

\subsection{Dependence of the $D$ retention in coatings on coating thickness}

Fig. 22 shows the D retention in W coatings produced by different methods

after the D plasma exposure as a function of the coating thickness. The D retention in CMSIIW coating increases linearly with the coating thickness, indicating the homogeneous distribution of intrinsic defects over the entire coating thickness. This dependence is less obvious in the case of the PLD-W coating because of lack of the data and data scatter. As discussed above, defects in PLD-W coating was not entirely saturated by D under the present exposure conditions. The thickness dependence is expected to be more clearly observed under appropriate exposure conditions (e.g. more fluences) where a homogeneous D distribution over the entire thickness can be obtained as seen in other coatings. Moreover, experiments with a-PLDW coatings are less reproducible compared to the case of CMSII coatings.

Consequently, we can state that the D retention strongly depends on both the coating crystalline structure and the thickness. A disadvantage of thin coating is its erosion which prevents the use of the coating under the long operation time. However, the tritium retention in thick W coatings under high temperature and high fluence can be a concern. 


\subsection{Temperature dependence of the $D$ retention in coatings}

New data together with collection of the data from [21] about temperature dependence of the $\mathrm{D}$ retention in CMSII-W coatings in comparison with polycrystalline bulk WI are shown in Fig. 23. The data were obtained from NRA measurements by integrating the D concentration over the depth up to $6 \mu \mathrm{m}$ and from TDS by integrating the D desorption rate over the time. In CMSII-W coatings, NRA data are only slightly lower than TDS data, indicating that the majority of $\mathrm{D}$ is retained in the coating itself and the less considerable part is retained in the substrate. In contrast, a comparison of the NRA and TDS data in the case of WI indicates that the majority part of D is retained in the bulk of WI far beyond the depth of 6 $\mu \mathrm{m}$ as it was also reported in early papers [2-4].

The D retention in CMSII-W coating with a thickness of $10 \mu \mathrm{m}$ is higher than that one in WI. No significant temperature dependence of the D retention in CMSII-W coating between 300 and $750 \mathrm{~K}$ reveals that the dominant intrinsic defects in the coating are defects with high binding energy for $\mathrm{D}$ such as vacancies and vacancy clusters/nano-pores. In contrast, the D retention in WI shows a slight increase with the exposure temperature up to around $500 \mathrm{~K}$ followed by a sharp decrease above $500 \mathrm{~K}$. This indicates that $\mathrm{D}$ trapping by dislocations and other defects with low binding energy mainly contributes to the total D retention in WI in contrast to CMSII-W coating. The local D super-saturation can result in local stress-induced formation of defects in WI and even in blister formation as it was reported in [2-4].

\section{Conclusions}


The disorder W coating produced by Pulsed Laser Deposition (PLD-W), the dense W coating produced by Combined Magnetron Sputtering and Ion Implantation (CMSII-W) technology and $\mathrm{W}$ coating produced by standard vacuum magnetron-sputtering (SMS-W) method were irradiated with D plasma. The D depth profile was measured up to $6.5 \mu \mathrm{m}$ by nuclear reaction analysis (NRA) and the total deuterium retention was measured by thermal desorption spectroscopy (TDS). We investigated a dependence of the D retention in a W coating on (i) the substrate material, (ii) the crystalline structure, namely, dense or disordered, (iii) the presence of $\mathrm{Ar}$ in the coating, (iv) the coating thickness and (v) the sample temperature during the D plasma exposure.

It was found that all types of coatings show higher D concentration compared to PCW. Among those coatings, the disordered PLD-W has the highest D concentration. The lowest D concentration was found in SMS-W coating produced without the extra substrate bias. Deposition parameters, such as gas pressure, argon ion implantation, temperature of substrate, and deposition rate, show direct effect on crystallite size and, therefore, on the D retention in a coating. On the other hand, it was found that the D retention does not significantly affect by the presence of $\mathrm{Ar}$ in the $\mathrm{W}$ coating. The $\mathrm{D}$ retention in a coating linearly increases with the coating thickness, indicating the homogeneous defect distribution over the overall thickness of coatings. Measurement of the temperature dependence of the $\mathrm{D}$ retention performed for CMSII-W coating showed no significant temperature dependence between 300 and $750 \mathrm{~K}$, meaning that the dominant $\mathrm{D}$ trapping sites in the coating are defects with high binding energy.

The conclusion drawn in [26] that the $\mathrm{D}$ concentration correlates with the crystalline structure of $\mathrm{W}$ was confirmed by numerous new experimental results: the D concentration is largest for $\mathrm{W}$ films with smallest crystallite size. This increase in the $\mathrm{D}$ retention with 
decreasing the grain size in $\mathrm{W}$ coatings is attributed to an increase of the density of vacancy clusters/nano-pores attached to grain boundaries.

Moreover, other factors of microstructure, such as porosity can also affect the D retention: the density of a-PLDW film is $\sim 60 \%$ less than the density of PCW and CMSII-W coating, indicating high porosity of a-PLDW coating which in turn leads to an increase in the D retention by trapping in the pores.

In CMSII-W coatings of $10 \mu \mathrm{m}$ of the thickness the majority part of $\mathrm{D}$ is retained in the coating itself and the less considerable part is retained in the substrate at present experimental conditions of the fluence of $2 \times 10^{25} \mathrm{D} / \mathrm{m}^{2}$ and sample temperatures ranged from 320 to $700 \mathrm{~K}$. Although substrate has minor effect on the D concentration in a coating, nevertheless, the choice of substrate material can affect the total D retention in such multilayer materials at high temperatures and high fluences.

\section{Acknowledgement}

We are grateful to G. Terraneo for XRD measurements, F. Koch for SMS-W coating production, G. Matern for SEM and FIB images and J. Dorner and M. Fußeder for technical assistance. We would like to thanks to M. Balden for fruitful discussion. This work was partly supported by the Impuls- und Vernetzungsfond der Helmholtz-Gemeinschaft e.V. and partly supported by Russian Science Foundation (RSF) grant №16-12-10332. 


\section{References}

[1] Causey R. A., 2002 J. Nucl. Mater. 30091

[2] Ogorodnikova O.V, Roth J., Mayer M., J. Nucl. Mater. 313-316 (2003) 469

[3] Ogorodnikova O.V., Roth J., Mayer M., J. Nucl. Mater. 373 (2008) 254

[4] Ogorodnikova O.V, Roth J., Mayer M., J. Appl. Phys. 103 (2008) 034902

[5] O. V. Ogorodnikova, T. Schwarz-Selinger, K. Sugiyama, T. Dürbeck, and W. Jacob, Phys. Scr. T138, (2009) 014053

[6] V.Kh. Alimov, B. Tyburska-Püschel, S. Lindig, Y. Hatano, M. Balden, J. Roth, K. Isobe, M. Matsuyama, T. Yamanishi, J. Nucl. Mater, 420 (2012) 519

[7] M. Poon, A.A. Haasz, J.W. Davis, J. Nucl. Mater. 374 (2008) 390.

[8] O.V. Ogorodnikova, B. Tyburska, V.Kh. Alimov, K. Ertl, Journal of Nuclear Materials, Volume 415, Issue 1, Supplement, 2011, p. S661

[9] G. M. Wright, M. Mayer, K. Ertl, G. de Saint-Aubin and J. Rapp, Nucl. Fus. 50, $075006(2010)$

[10] Y. Hatano et al., Nucl. Fus. 53, 073006 (2013)

[11] O. V. Ogorodnikova, Ł. Ciupiński, J. Grzonka, Yu. Gasparyan, V. Efimov, J. Nucl. Mater, 451 (2014) 379

[12] O. V. Ogorodnikova and V. Gann, J. Nucl. Mater., 460 (2015), 60

[13] O. V. Ogorodnikova, S. Markelj, U. von Toussant, J. Appl. Phys, 119 (2016) 054901

[14] R.A. Pitts, S. Carpentier, F. Escourbiac, et al. J. Nucl. Mater. 438 (2013) S48

[15] J. Roth, E. Tsitrone, Th. Loarer, V. Philipps, S. Brezinsek, A. Loarte, G. F. Counsell, R. P Doerner, K. Schmid, O. V. Ogorodnikova, R. A. Causey, Plasma Physics and Controlled Fusion. 2008; 50(10) 103001 
[17] K. Sugiyama, M. Mayer, V. Rohde, M. Balden, Th. Dürbeck, A. Herrmann, S. Lindig, A. Wiltner, H.W. Müller, R. Neu and the ASDEX Upgrade team, Nucl. Fusion 50 (2010) 035001

[18] K. Sugiyama, M. Mayer, A. Herrmann, K. Krieger, V. Rohde, M. Balden, S. Lindig, R. Neu, H.W. Müller and the ASDEX Upgrade team, Phys. Scr. T149 (2014) 014043

[19] V. Kh. Alimov, B. Tyburska, O.V. Ogorodnikova, J. Roth, K. Isobe, T. Yamanishi, J. Nucl. Mater, 415 (2011) S628

[20] V.Kh. Alimov, H. Nakamura, B. Tyburska-Püschel, O.V. Ogorodnikova, J. Roth, K. Isobe, T. Yamanishi, Journal of Nuclear Materials, Volume 414, Issue 3, 2011, p. 479

[21] O. V. Ogorodnikova, K. Sugiyama, T. Schwarz-Selinger, T. Dürbeck, M. Balden, J. Nucl. Mater, 419 (2011) 194

[22] O.V. Ogorodnikova and K. Sugiyama, J. Nucl. Mater, 442 (2013) 518

[23] C. Ruset, E. Grigore, H. Maier, R. Neu, H. Greuner, M. Mayer, G. Matthews, Fusion Engineering and Design, 86, 9-11, (2011) 1677

[24] C. Ruset, E. Grigore, H. Maier, R. Neu, X. Li, H. Dong, R. Mitteau, X. Courtois and JET-EFDA Contributors, Phys. Scr. T128 (2007) 171

[25] G.F. Matthews et al., J. Nucl. Mater. 390-391 (2009) 934

[26] O.V. Ogorodnikova, J. Appl. Phys., 122, 044902 (2017)

[27] K. Kaneko, Y. Furuya, M. Kijuchi, Fusion Eng. Des. 19 (1992) 293

[28] Chimi, Y. et al. J. Nucl. Mater. 297, 355-357 (2001).

[29] A. Kilmametov et al. Radiat. Eff. Defects Solids. 167-8, 631-639 (2012)

[30] D. Dellasega, G. Merlo, C. Conti, C.E. Bottani, M. Passoni, J. Appl. Phys., 112, 084328 (2012). 
[31] D. Dellasega, S.M. Pietralunga, A. Pezzoli, V. Russo, L. Nasi, C. Conti, M.J. Vahid, A. Tagliaferri, M. Passoni (2015) Nanotechnology, 26 (36), 365601

[32] P. Scherrer, Göttinger Nachrichten Gesell., Vol. 2, 1918, p 98.

[33] A. Manhard, T. Schwarz-Selinger, W. Jacob, Plasma Sources Sci. Technol. 20 (2011) 015010

[34] M. Mayer, E. Gauthier, K. Sugiyama, U. von Toussaint, Nucl. Instr. Meth. B 267 (2009) 506

[35] A. Rusinov, Yu. Gasparyan, S. Perelygin, A. Pisarev, S. Stepanov, N. Trifonov, Instruments and Experimental Techniques 52 (2009) 871-876

[36] C. Ruset, E. Grigore, I. Munteanu, H. Maier, H. Greuner, C. Hopf, V. Phylipps, G. Matthews, JET-EFDA Contributors, Fusion Engineering and Design 84 (2009) 1662-1665

[37] O.V. Ogorodnikova, X. Raepsaet, M.A. Futterer. Fus. Eng. Des., 49921 (2000).

[38] S. Brezinsek et al., J. Nucl. Mater. 438 (2013) S303-S308 


\section{Figure captions}

Fig. 1. SEM images of CMSII-W coatings deposited on fine grain graphite (FGG): (a) nanocrystalline CMSII-W produced with standard run and (b) nanocrystalline CMSII-W produced with the oscillating jigging device (cauliflower-like).

Fig. 2. SEM images of SMS-W coatings deposited on FGG: (a) SMS-W coating produced without Ar ion implantation and (b) SMS-W coating produced with Ar ion implantation.

Fig. 3. (a) SEM image of amorphous-like a-PLDW coating with a thickness of $1 \mu \mathrm{m}$ deposited on FGG substrate. (b) Cross sectional SEM images observed at $38^{\circ}$ tilting of the multilayer system consisting of $1 \mu \mathrm{m}$ thick a-PLDW film and $150 \mathrm{~nm}$ thick c-PLDW film deposited on silicon ( $\mathrm{Si}$ ) substrate as a reference. A magnification of the interface is present in the inset.

Fig. 4. XRD analysis of: top) the multilayer system: $1 \mu \mathrm{m}$ of a-PLDW film and $150 \mathrm{~nm}$ of cPLDW on fine grain graphite (FGG) and bottom) the bare FGG substrate. The XRD reflections related to $\mathrm{W}$ have been fitted with Lorentzian functions with the aim of decouple the contributions of W films and substrate. Both c-PLDW and a-PLDW films on FGG have a preferred orientation of (110) planes perpendicular to the surface.

Fig. 5. XRD of CMSII-W and SMS-W coatings deposited on Eurofer and FGG substrates. The nano-sized grains of CMSII-W deposited on Eurofer substrate possess a preferred orientation of (211) planes parallel to the surface. SMS-W coatings deposited on FGG and Eurofer substrates without Ar ion implantation have grains with preferential orientation of (110) and SMS-W coatings deposited on FGG with Ar ion implantation have grains with preferential orientation of (200). The similar data for both coatings deposited on FGG and CFC using the same deposition parameters were obtained. 
Fig. 6. Cross sectional SEM images observed at $38^{\circ}$ tilting of a) CMSII-W coating with a thickness of $10 \mu \mathrm{m}$ on Eurofer substrate using Mo interlayer with a thickness of $3 \mu \mathrm{m}$ and b) SMS-W coating with a thickness of $3 \mu \mathrm{m}$ (without Ar implantation) on Eurofer substrate.

Fig. 7. D depth profiles in CMSII-W coatings with a thickness of $10 \mu \mathrm{m}$ deposited on Eurofer; FGG, and CFC substrates using Mo interlayer with a thickness of $3 \mu \mathrm{m}$ between the coating and the substrate in comparison with D depth profiles in polycrystalline tungsten, WI (ITER grade) and WR (recrystallized tungsten) taking from [26]. The CMSII-W film was deposited on two kinds of CFC: with fibres oriented to be parallel (CFC II) and perpendicular (CFC $\perp$ ) to the deposited surface. Deuterium was implanted in samples by ECR plasma source with ion energy of $20 \mathrm{eV}$ per D atom up to a fluence of $F=2.2 \times 10^{25} \mathrm{D} / \mathrm{m}^{2}$ at sample temperature of 600 K.

Fig. 8. TDS of D from CMSII-W coatings with a thickness of $10 \mu \mathrm{m}$ deposited on Eurofer, FGG, and CFC substrates in comparison with TDS of D from polycrystalline tungsten, WI (ITER grade), and from bare Eurofer. The CMSII-W film was deposited on two kinds of CFC: with fibres oriented to be parallel (CFC II) and perpendicular (CFC $\perp$ ) to the deposited surface. Dashed lines are shown the fitting of board TDS peak from CMSII-W coating on Eurofer substrate by two Gaussian peaks. Deuterium was implanted in samples by ECR plasma source with ion energy of $20 \mathrm{eV}$ per $\mathrm{D}$ atom up to a fluence of $F=2.2 \times 10^{25} \mathrm{D} / \mathrm{m}^{2}$ at sample temperature of $600 \mathrm{~K}$.

Fig. 9. D depth profiles in CMSII-W coatings with a thickness of $3 \mu \mathrm{m}$ deposited on Eurofer (indicated as Eur) with and without Mo interlayer. One CMSII-W coating with Mo interlayer was annealed at $1000 \mathrm{~K}$ for 10 minutes prior to the plasma exposure. Deuterium was implanted in samples by ECR plasma source with ion energy of $20 \mathrm{eV}$ per $\mathrm{D}$ atom up to a fluence of 
$F=2.2 \times 10^{25} \mathrm{D} / \mathrm{m}^{2}$ at sample temperature of $600 \mathrm{~K}$. Dashed vertical lines indicate an interface between different materials.

Fig. 10. TDS of D from CMSII-W coatings with a thickness of $3 \mu \mathrm{m}$ deposited on Eurofer with and without Mo interlayer in comparison with TDS of D from CMSII-W coating with a thickness of $10 \mu \mathrm{m}$ deposited on Eurofer with Mo interlayer. Deuterium was implanted in samples by ECR plasma source with ion energy of $20 \mathrm{eV}$ per $\mathrm{D}$ atom up to a fluence of $F=2.2 \times 10^{25} \mathrm{D} / \mathrm{m}^{2}$ at sample temperature of $600 \mathrm{~K}$.

Fig. 11. D depth profiles in CMSII-W coatings with a thickness of $10 \mu \mathrm{m}$ deposited on Eurofer (indicated as Eur) with Mo interlayer. One sample was annealed at $1000 \mathrm{~K}$ for 10 minutes prior to the plasma exposure. Deuterium was implanted in samples by ECR plasma source with ion energy of $20 \mathrm{eV}$ per $\mathrm{D}$ atom up to a fluence of $F=2.2 \times 10^{25} \mathrm{D} / \mathrm{m}^{2}$ at sample temperature of $600 \mathrm{~K}$.

Fig. 12. TDS of D from CMSII-W coatings with a thickness of $10 \mu \mathrm{m}$ deposited on Eurofer with Mo interlayer (CMSII-W/Mo/Eurofer). One CMSII-W coating was annealed at $1000 \mathrm{~K}$ for 10 minutes prior to the plasma exposure. TDS of D from polycrystalline tungsten, WI (ITER grade), is also shown for comparison. Deuterium was implanted in samples by ECR plasma source with ion energy of $20 \mathrm{eV}$ per $\mathrm{D}$ atom up to a fluence of $F=2.2 \times 10^{25} \mathrm{D} / \mathrm{m}^{2}$ at sample temperature of $600 \mathrm{~K}$.

Fig. 13. D depth profiles in Eurofer 'as received' and annealed at $1200 \mathrm{~K}$ prior to the plasma exposure. Deuterium was implanted in samples by ECR plasma source with ion energy of $200 \mathrm{eV}$ per D atom up to a fluence of $F=6 \times 10^{24} \mathrm{D} / \mathrm{m}^{2}$ at sample temperature of $290 \mathrm{~K}$.

Fig. 14. D depth profiles in CMSII-W coatings with different thicknesses on Eurofer (indicated as Eur), CFC and FGG substrates. Two arrows indicate interfaces (i) between CMSII-W coating and Mo interlayer and (ii) between Mo interlayer and Eurofer substrate, respectively, 
in the case of CMSII-W coating with a thickness of $3.5 \mu \mathrm{m}$. SEM pictures of the different structure of coatings deposited with the oscillating jigging device and standard run are shown on the right side. Three upper curves for coatings produced with the oscillating jigging device are belong to the top SEM picture and they have smaller grain size than four bottom curves for coatings produced with standard run which are belong to the bottom SEM picture and they have bigger grain size. Deuterium was implanted in samples by ECR plasma source with ion energy of $20 \mathrm{eV}$ per $\mathrm{D}$ atom up to a fluence of $F=2.2 \times 10^{25} \mathrm{D} / \mathrm{m}^{2}$ at sample temperature of 370 K.

Fig. 15. D depth profiles in $\mathrm{W}$ coatings with a thickness of $\sim 3 \mu \mathrm{m}$ on Eurofer taking from [26] in comparison with new data for SMS-W coatings with and without Ar ion implantation (with and without extra bias) during the deposition. Deuterium was implanted in samples by ECR plasma source with ion energy of $20 \mathrm{eV}$ per $\mathrm{D}$ atom up to a fluence of $F=2.2 \times 10^{25} \mathrm{D} / \mathrm{m}^{2}$ at sample temperature of $600 \mathrm{~K}$. Dashed vertical line indicates an interface between a coating and Eurofer substrate.

Fig. 16. TDS of $\mathrm{D}$ from $\mathrm{W}$ coatings with a thickness of $3 \mu \mathrm{m}$ produced by different methods on Eurofer substrate after the D plasma exposure with $20 \mathrm{eV}$ at $600 \mathrm{~K}$ up to a fluence of $2.2 \times 10^{25} \mathrm{D} / \mathrm{m}^{2}$

Fig. 17. Normalized TDS (from Fig. 16) of D from W coatings with a thickness of $3 \mu \mathrm{m}$ produced by different methods on Eurofer in comparison with normalized TDS (from Fig. 8) of $\mathrm{D}$ from polycrystalline WI after the D plasma exposure with $20 \mathrm{eV}$ at $600 \mathrm{~K}$ up to a fluence of $2.2 \times 10^{25} \mathrm{D} / \mathrm{m}^{2}$.

Fig. 18. TDS of D from nano-crystalline columnar-like c-PLDW coating with a thickness of $150 \mathrm{~nm}$ on FGG (150 nm c-PLDW/FGG) and amorphous-like a-PLDW coating with a thickness of $1 \mu \mathrm{m}$ on FGG with $150 \mathrm{~nm}$ c-PLDW interlayer $(1 \mu \mathrm{m}$ a-PLDW/150nm c- 
PLDW/FGG). TDS of D from two polycrystalline tungsten samples, WI, are also shown for comparison. Deuterium was implanted in samples by ECR plasma source with ion energy of 20 eV per D atom up to a fluence of $F=2.2 \times 10^{25} \mathrm{D} / \mathrm{m}^{2}$ at sample temperature of $600 \mathrm{~K}$.

Fig. 19. Some examples of TDS of Ar from SMS-W coatings with a thickness of $3 \mu \mathrm{m}$ deposited on FGG substrate with (dashed lines) and without (solid lines) extra bias applied to the substrate.

Fig. 20. D depth profiles in SMS-W coating with a thickness of $\sim 3 \mu \mathrm{m}$ on a) FGG and b) Eurofer with and without Ar ion implantation during the deposition. SEM pictures of the different structure of coatings deposited with and without Ar ion implantation are shown on the right side. Deuterium was implanted in samples by ECR plasma source with ion energy of 20 eV per D atom up to a fluence of $F=2.2 \times 10^{25} \mathrm{D} / \mathrm{m}^{2}$ at sample temperature of $600 \mathrm{~K}$.

Fig. 21. TDS of D from SMS-W coatings with a thickness of $3 \mu \mathrm{m}$ deposited on Eurofer and FGG substrates. The SMS-W coatings deposited with Ar ion implantation have smaller grain size compared to SMS-W coatings deposited without Ar ion implantation. One SMS-W coating deposited with Ar ion implantation on FGG was pre-annealed at $1273 \mathrm{~K}$ for 10 minutes prior to the plasma exposure. Deuterium was implanted in samples by ECR plasma source with ion energy of $20 \mathrm{eV}$ per $\mathrm{D}$ atom up to a fluence of $F=2.2 \times 10^{25} \mathrm{D} / \mathrm{m}^{2}$ at sample temperature of $600 \mathrm{~K}$.

Fig. 22. The D retention in $\mathrm{W}$ coatings produced by different methods on FGG and Eurofer (indicated as Eur) after the D plasma exposure with $20 \mathrm{eV}$ at $600 \mathrm{~K}$ up to a fluence of $2.2 \times 10^{25} \mathrm{D} / \mathrm{m}^{2}$ as a function of the coating thickness. The D retention was calculated from NRA measurements by integrating the D concentration over the depth of the tungsten coating.

Fig. 23. The D retention in CMSII-W coating on different substrates calculated from TDS by integrating the D desorption rate over the time (open symbols) and from NRA by integrating 
the D concentration over the depth (solid symbols) in comparison with polycrystalline W ITER grade, WI. For some samples, NRA data are not shown because they coincide with TDS data. 

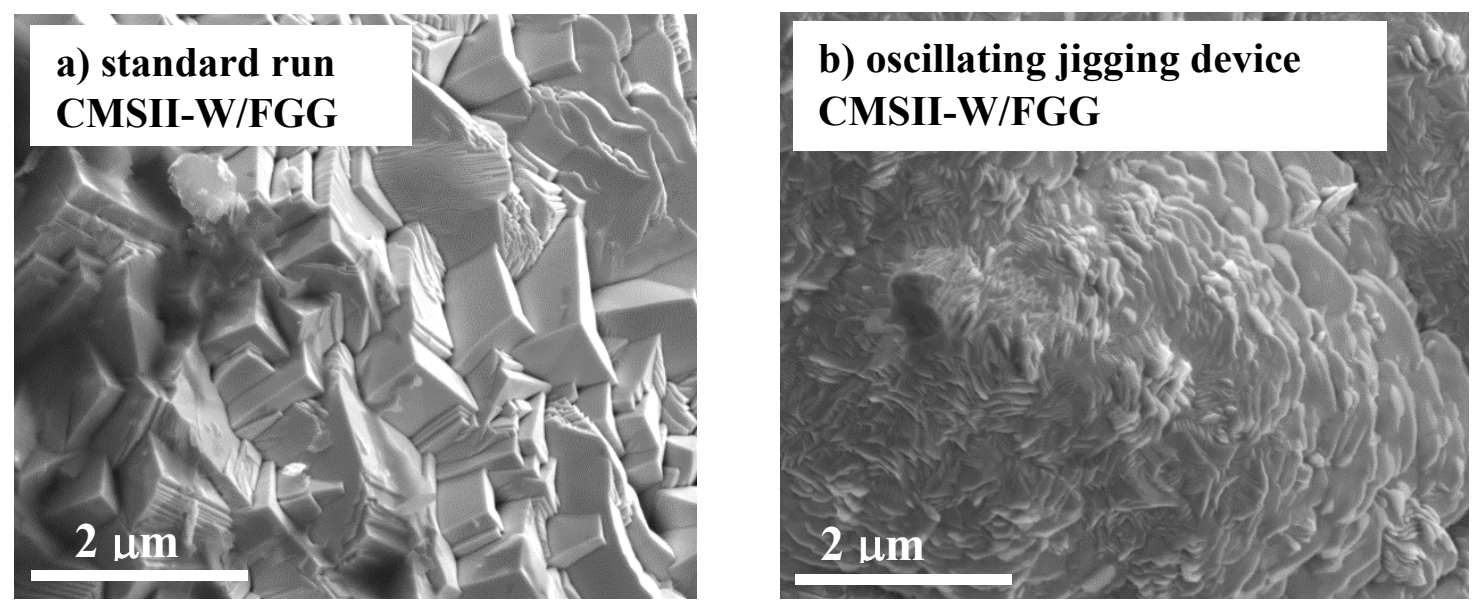

Fig. 1. SEM images of CMSII-W coatings deposited on fine grain graphite (FGG). (a) nanocrystalline CMSII-W produced with standard run and (b) nanocrystalline CMSII-W produced with the oscillating jigging device (cauliflower-like). 

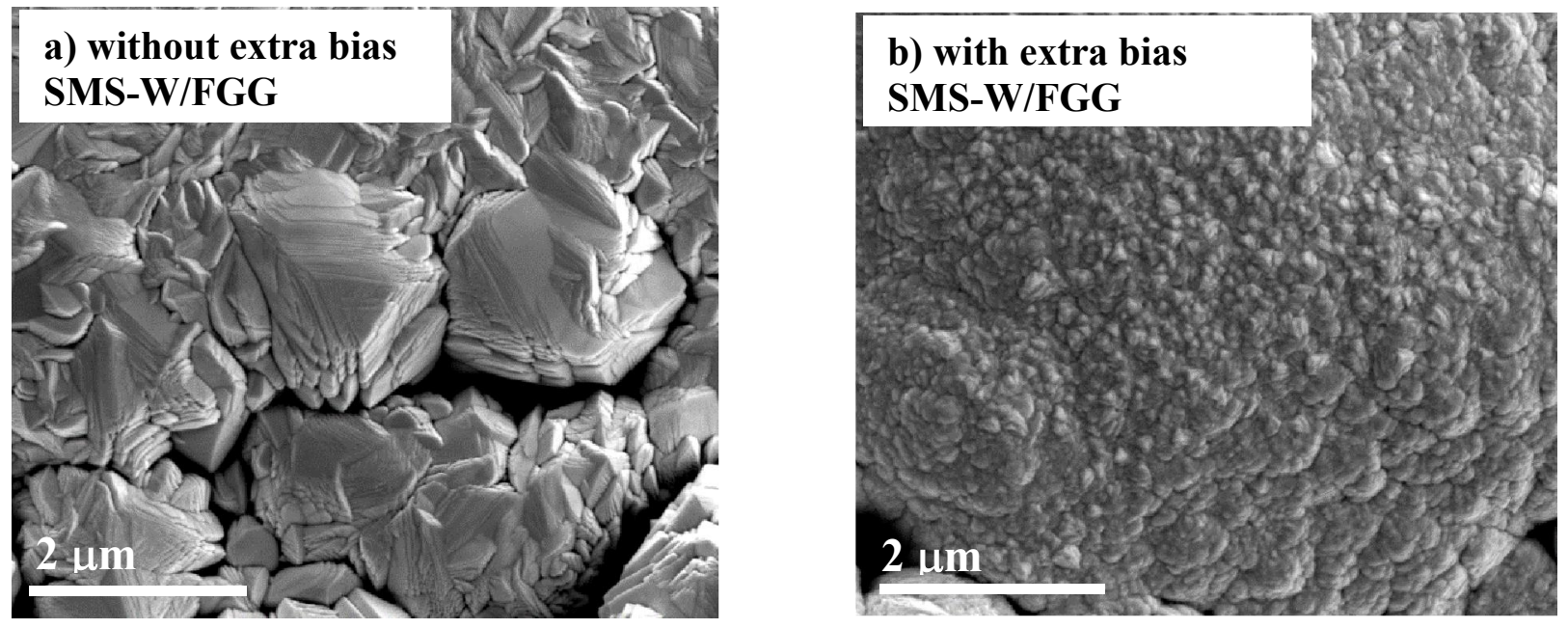

Fig. 2. SEM images of SMS-W coatings deposited on FGG. (a) SMS-W coating produced without Ar ion implantation and (b) SMS-W coating produced with Ar ion implantation. 

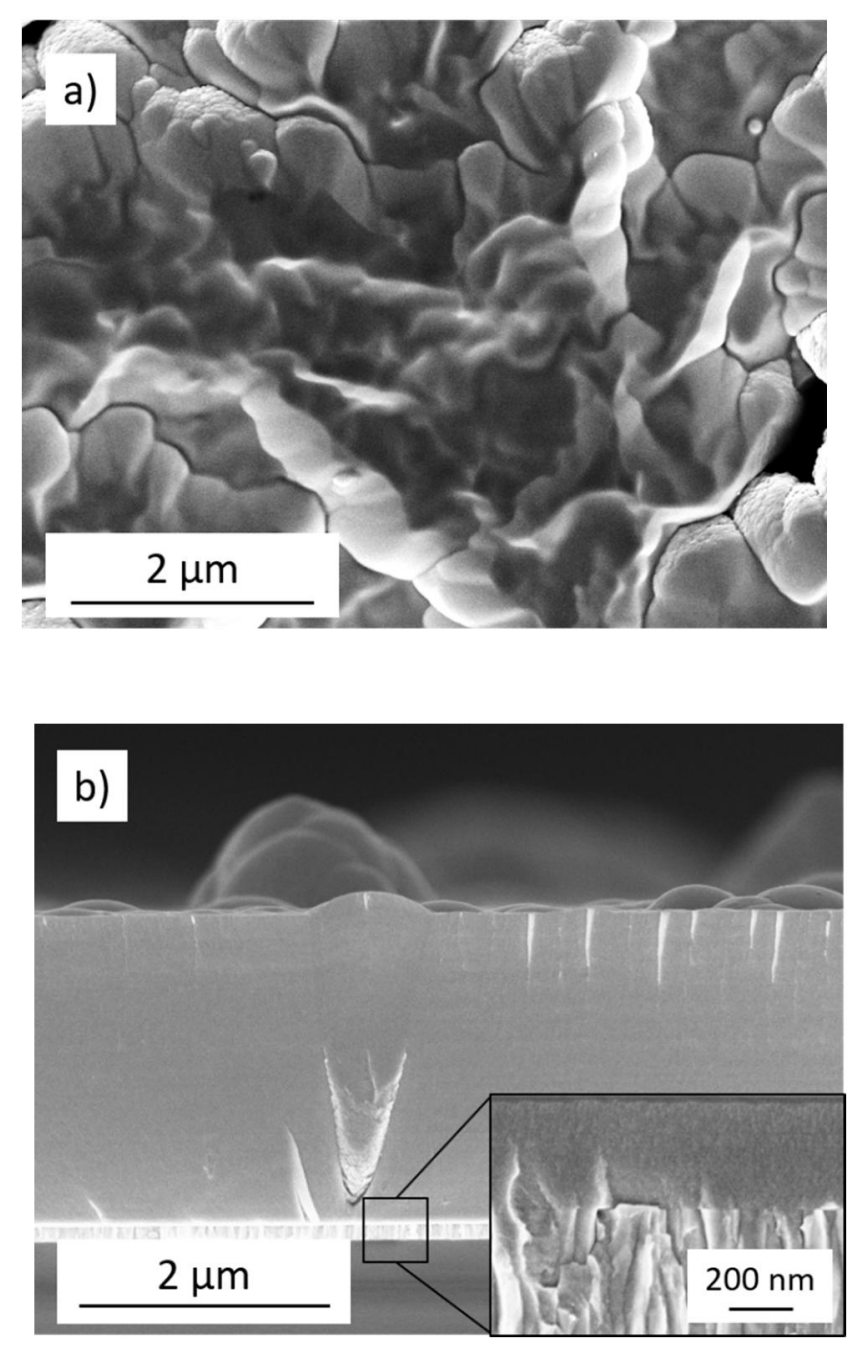

Fig. 3. (a) SEM image of amorphous-like a-PLDW coating with a thickness of $1 \mu \mathrm{m}$ deposited on FGG substrate. (b) Cross sectional SEM images observed at $38^{\circ}$ tilting of the multilayer system consisting of $1 \mu \mathrm{m}$ thick a-PLDW film and $150 \mathrm{~nm}$ thick c-PLDW film deposited on silicon (Si) substrate as a reference. A magnification of the interface is present in the inset. 


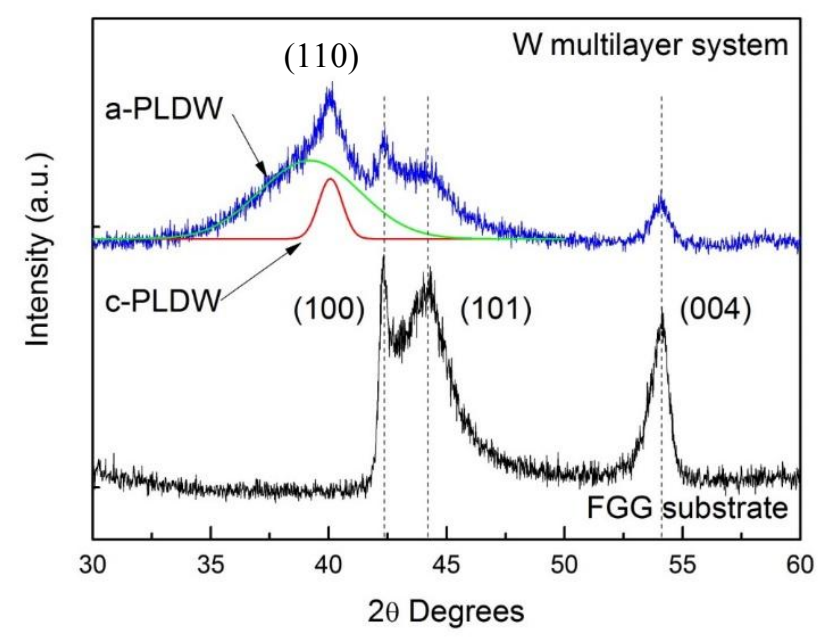

Fig. 4. XRD analysis of: top) the multilayer system: $1 \mu \mathrm{m}$ of a-PLDW film and $150 \mathrm{~nm}$ of cPLDW on fine grain graphite (FGG) and bottom) the bare FGG substrate. The XRD reflections related to $\mathrm{W}$ have been fitted with Lorentzian functions with the aim of decouple the contributions of W films and substrate. Both c-PLDW and a-PLDW films on FGG have a preferred orientation of (110) planes perpendicular to the surface. 


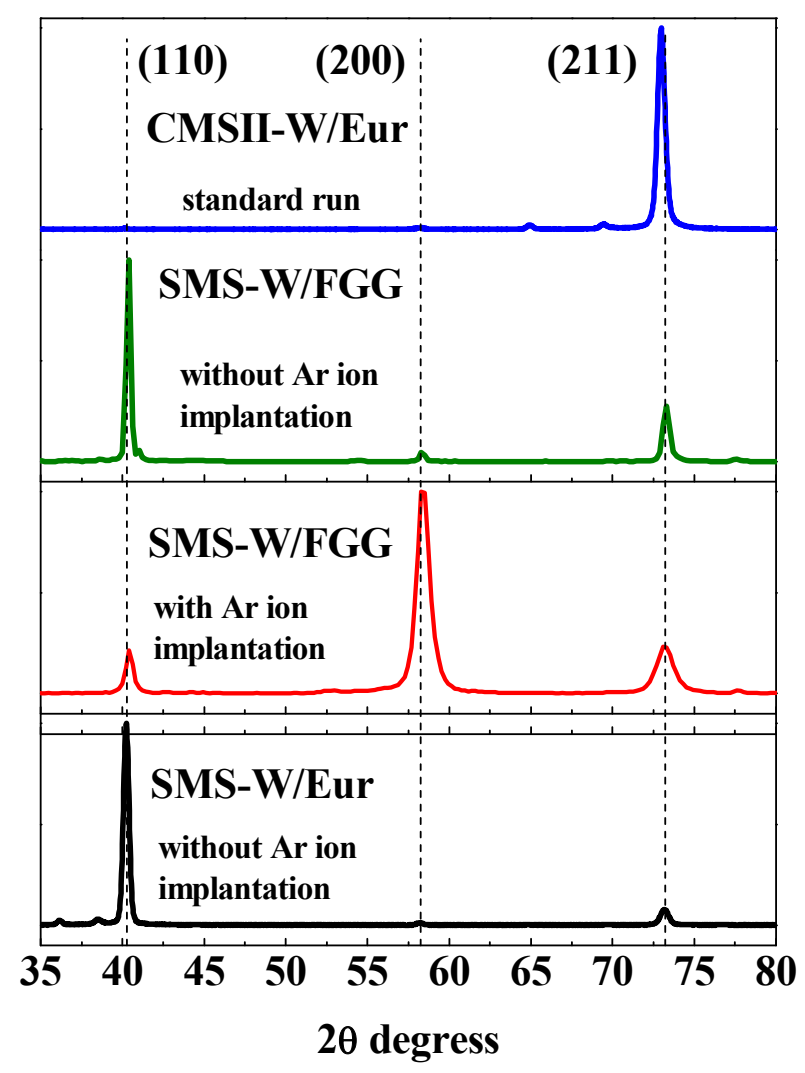

Fig. 5. XRD of CMSII-W and SMS-W coatings deposited on Eurofer and FGG substrates. The nano-sized grains of CMSII-W deposited on Eurofer substrate possess a preferred orientation of (211) planes parallel to the surface. SMS-W coatings deposited on FGG and Eurofer substrates without Ar ion implantation have grains with preferential orientation of (110) and SMS-W coatings deposited on FGG with Ar ion implantation have grains with preferential orientation of (200). The similar data for both coatings deposited on FGG and CFC using the same deposition parameters were obtained. 

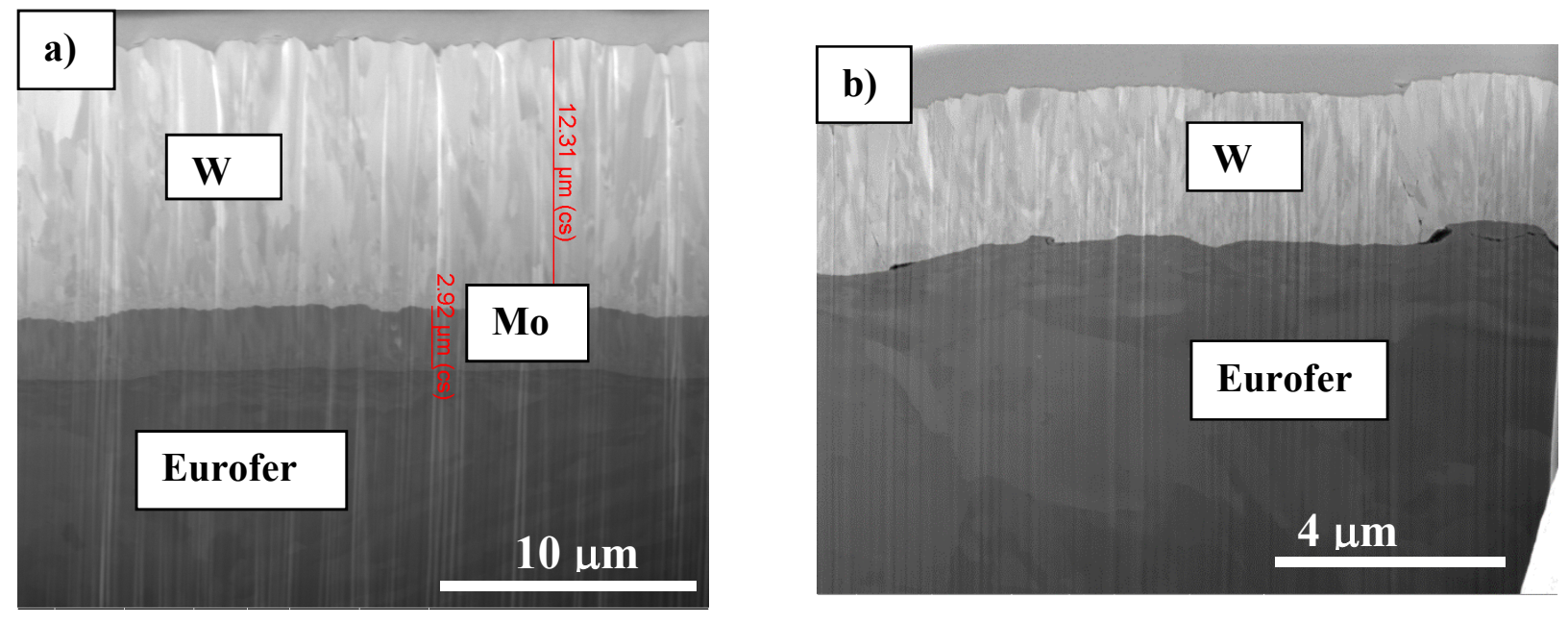

Fig. 6. Cross sectional SEM images observed at $38^{\circ}$ tilting of a) CMSII-W coating with a thickness of $10 \mu \mathrm{m}$ on Eurofer substrate using Mo interlayer with a thickness of $3 \mu \mathrm{m}$ and $\mathrm{b}$ ) SMS-W coating with a thickness of $3 \mu \mathrm{m}$ (without Ar implantation) on Eurofer substrate. 


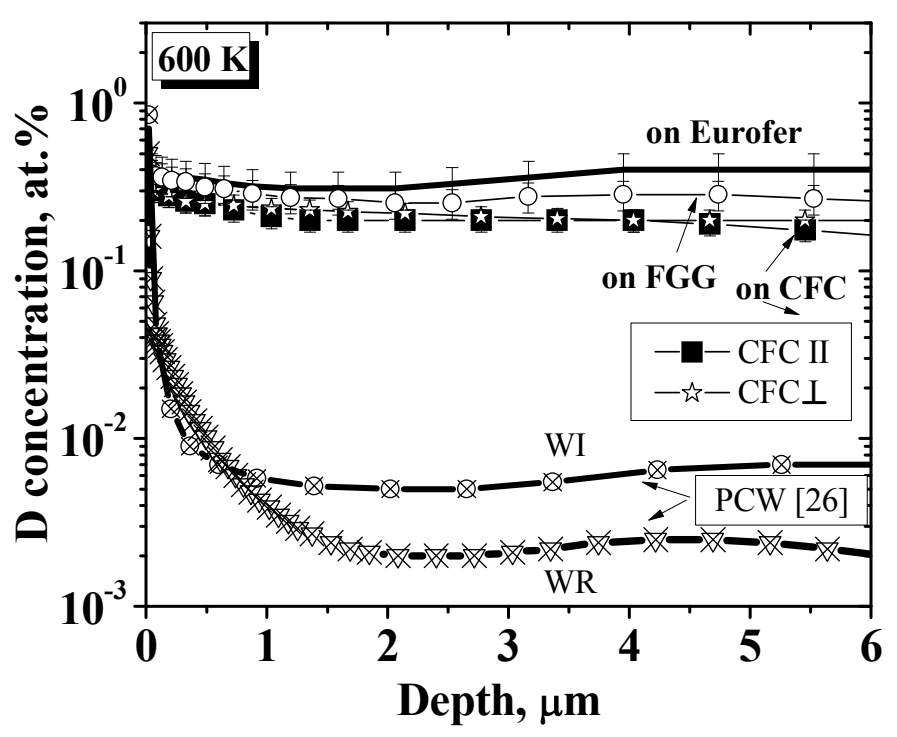

Fig. 7. D depth profiles in CMSII-W coatings with a thickness of $10 \mu \mathrm{m}$ deposited on Eurofer; FGG, and CFC substrates using Mo interlayer with a thickness of $3 \mu \mathrm{m}$ between the coating and the substrate in comparison with D depth profiles in polycrystalline tungsten, WI (ITER grade) and WR (recrystallized tungsten) taking from [26]. The CMSII-W film was deposited on two kinds of CFC: with fibres oriented to be parallel (CFC II) and perpendicular (CFC $\perp)$ to the deposited surface. Deuterium was implanted in samples by ECR plasma source with ion energy of $20 \mathrm{eV}$ per D atom up to a fluence of $F=2.2 \times 10^{25} \mathrm{D} / \mathrm{m}^{2}$ at sample temperature of $600 \mathrm{~K}$. 


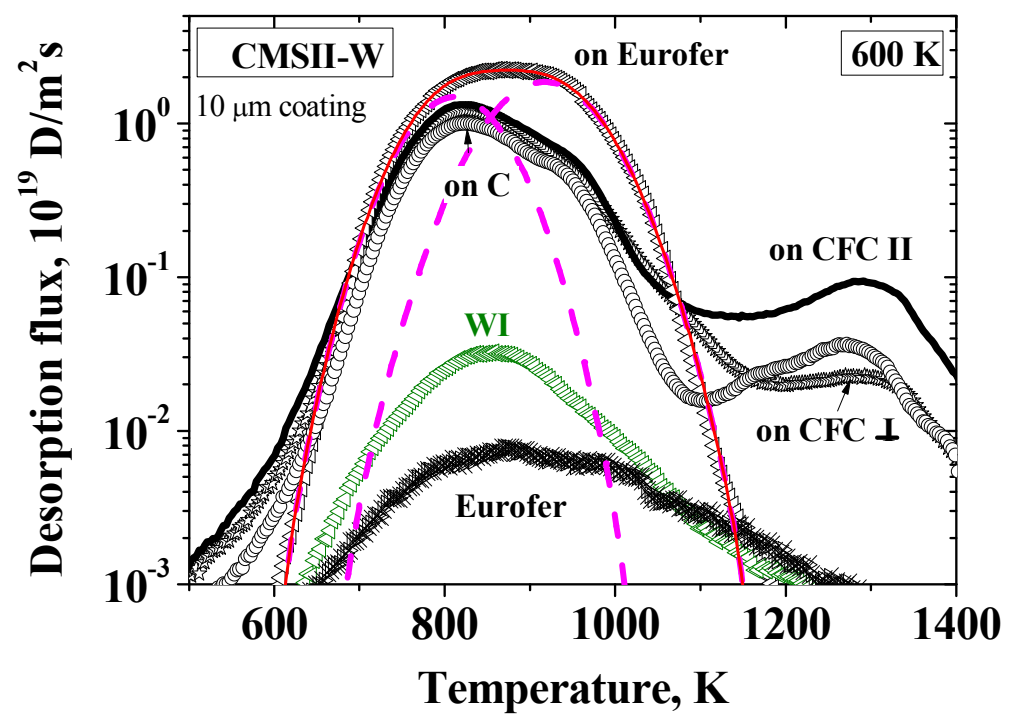

Fig. 8. TDS of D from CMSII-W coatings with a thickness of $10 \mu \mathrm{m}$ deposited on Eurofer, FGG, and CFC substrates in comparison with TDS of D from polycrystalline tungsten, WI (ITER grade), and from bare Eurofer. The CMSII-W film was deposited on two kinds of CFC: with fibres oriented to be parallel (CFC II) and perpendicular $(\mathrm{CFC} \perp)$ to the deposited surface. Dashed lines are shown the fitting of board TDS peak from CMSII-W coating on Eurofer substrate by two Gaussian peaks. Deuterium was implanted in samples by ECR plasma source with ion energy of 20 $\mathrm{eV}$ per $\mathrm{D}$ atom up to a fluence of $F=2.2 \times 10^{25} \mathrm{D} / \mathrm{m}^{2}$ at sample temperature of $600 \mathrm{~K}$. 


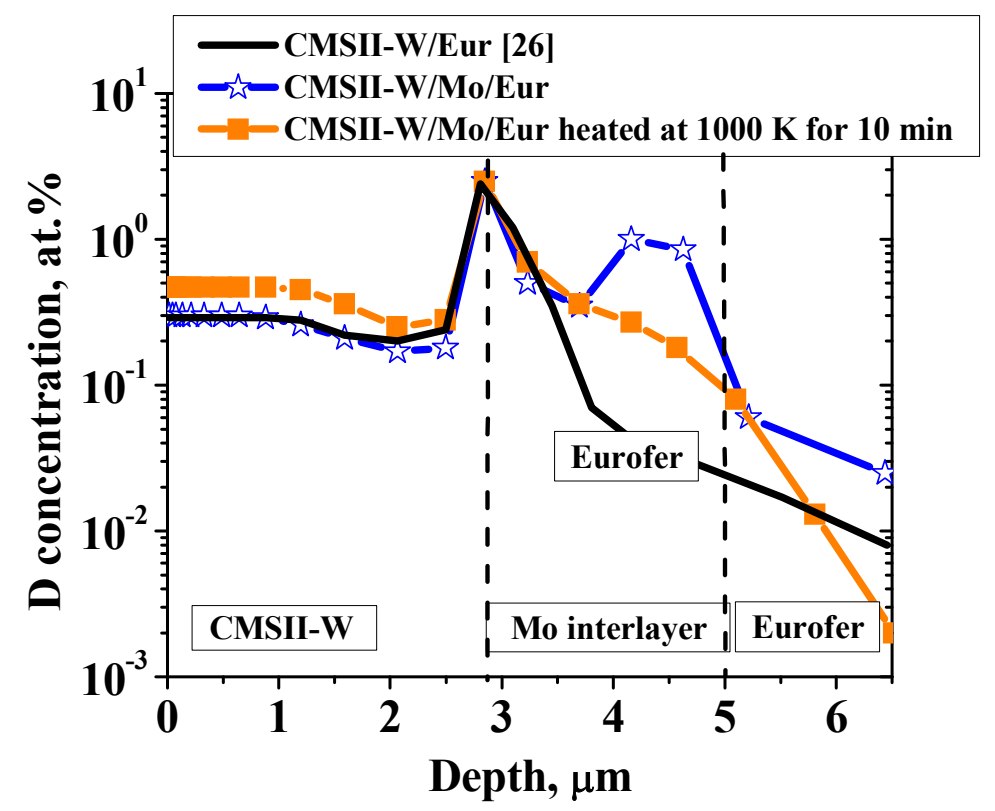

Fig. 9. D depth profiles in CMSII-W coatings with a thickness of $3 \mu \mathrm{m}$ deposited on Eurofer (indicated as Eur) with and without Mo interlayer. One CMSII-W coating with Mo interlayer was annealed at $1000 \mathrm{~K}$ for 10 minutes prior to the plasma exposure. Deuterium was implanted in samples by ECR plasma source with ion energy of $20 \mathrm{eV}$ per D atom up to a fluence of $F=2.2 \times 10^{25}$ $\mathrm{D} / \mathrm{m}^{2}$ at sample temperature of $600 \mathrm{~K}$. Dashed vertical lines indicate an interface between different materials. 


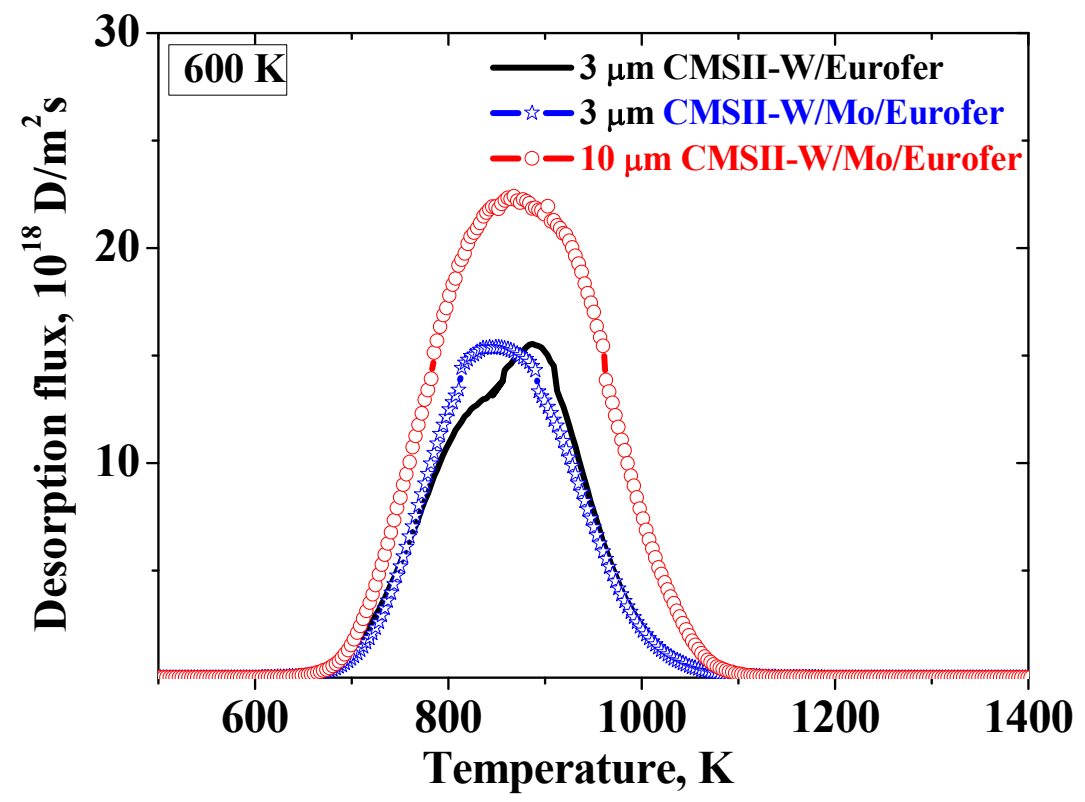

Fig. 10. TDS of D from CMSII-W coatings with a thickness of $3 \mu \mathrm{m}$ deposited on Eurofer with and without Mo interlayer in comparison with TDS of D from CMSII-W coating with a thickness of 10 $\mu \mathrm{m}$ deposited on Eurofer with Mo interlayer. Deuterium was implanted in samples by ECR plasma source with ion energy of $20 \mathrm{eV}$ per $\mathrm{D}$ atom up to a fluence of $F=2.2 \times 10^{25} \mathrm{D} / \mathrm{m}^{2}$ at sample temperature of $600 \mathrm{~K}$. 


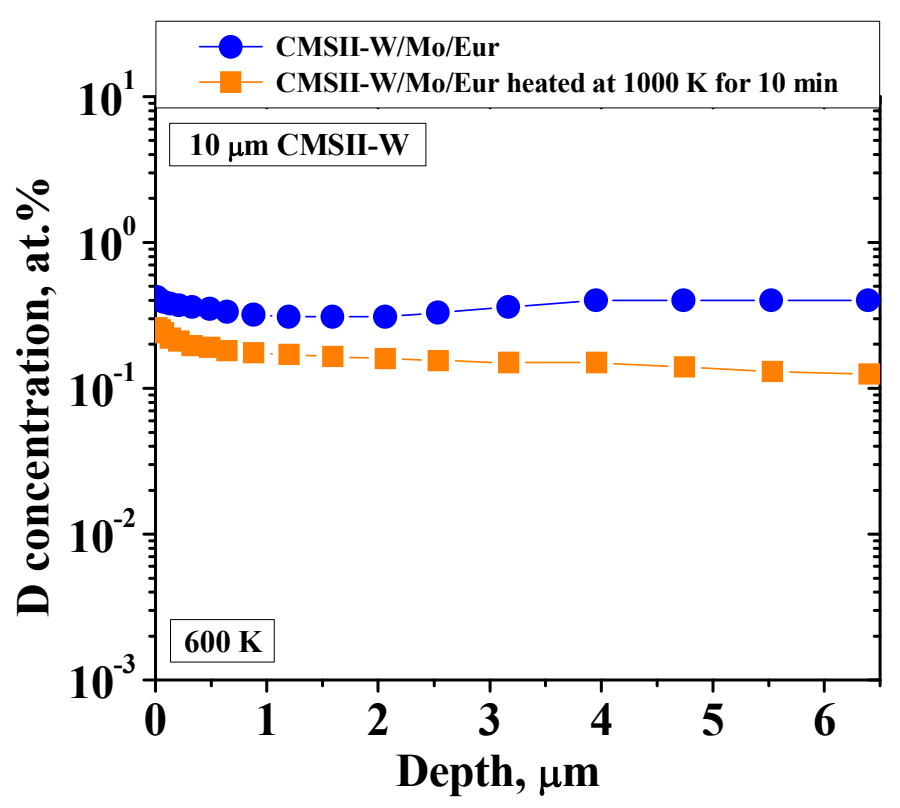

Fig. 11. D depth profiles in CMSII-W coatings with a thickness of $10 \mu \mathrm{m}$ deposited on Eurofer (indicated as Eur) with Mo interlayer. One sample was annealed at $1000 \mathrm{~K}$ for 10 minutes prior to the plasma exposure. Deuterium was implanted in samples by ECR plasma source with ion energy of $20 \mathrm{eV}$ per D atom up to a fluence of $F=2.2 \times 10^{25} \mathrm{D} / \mathrm{m}^{2}$ at sample temperature of $600 \mathrm{~K}$. 



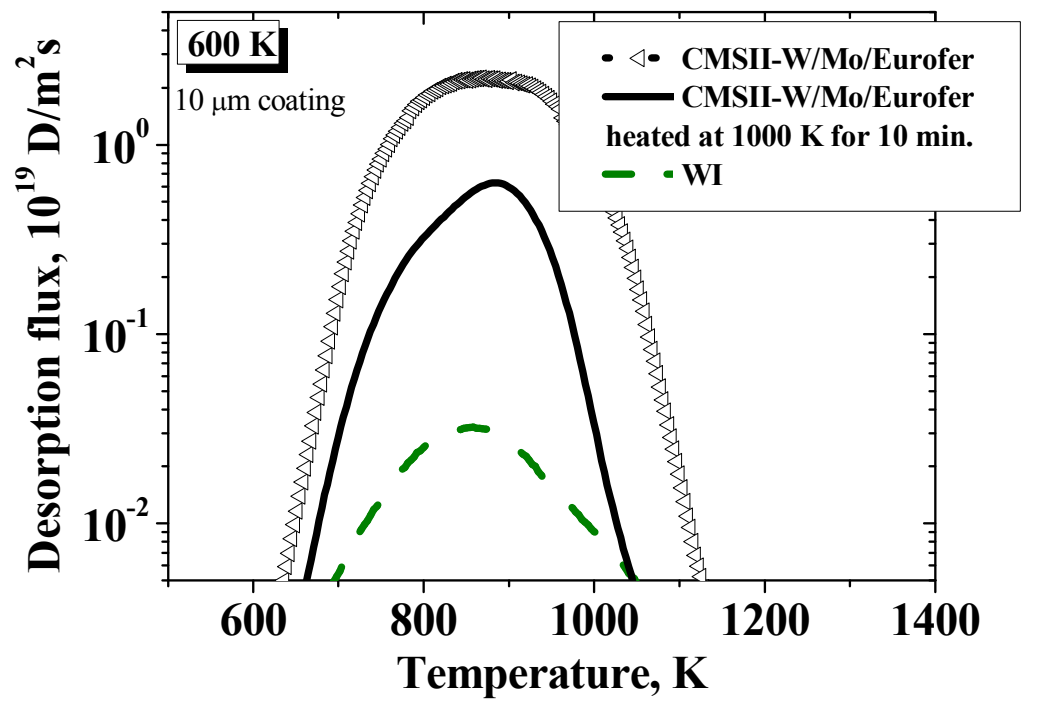

Fig. 12. TDS of D from CMSII-W coatings with a thickness of $10 \mu \mathrm{m}$ deposited on Eurofer with Mo interlayer (CMSII-W/Mo/Eurofer). One CMSII-W coating was annealed at $1000 \mathrm{~K}$ for 10 minutes prior to the plasma exposure. TDS of D from polycrystalline tungsten, WI (ITER grade), is also shown for comparison. Deuterium was implanted in samples by ECR plasma source with ion energy of $20 \mathrm{eV}$ per D atom up to a fluence of $F=2.2 \times 10^{25} \mathrm{D} / \mathrm{m}^{2}$ at sample temperature of $600 \mathrm{~K}$. 


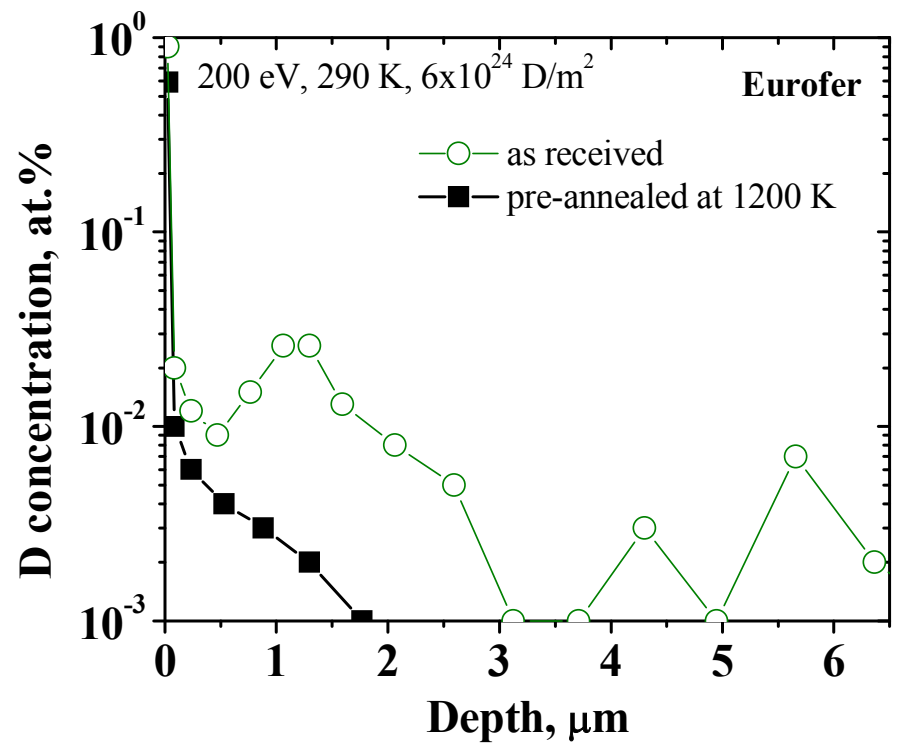

Fig. 13. D depth profiles in Eurofer 'as received' and annealed at $1200 \mathrm{~K}$ prior to the plasma exposure. Deuterium was implanted in samples by ECR plasma source with ion energy of $200 \mathrm{eV}$ per D atom up to a fluence of $F=6 \times 10^{24} \mathrm{D} / \mathrm{m}^{2}$ at sample temperature of $290 \mathrm{~K}$. 


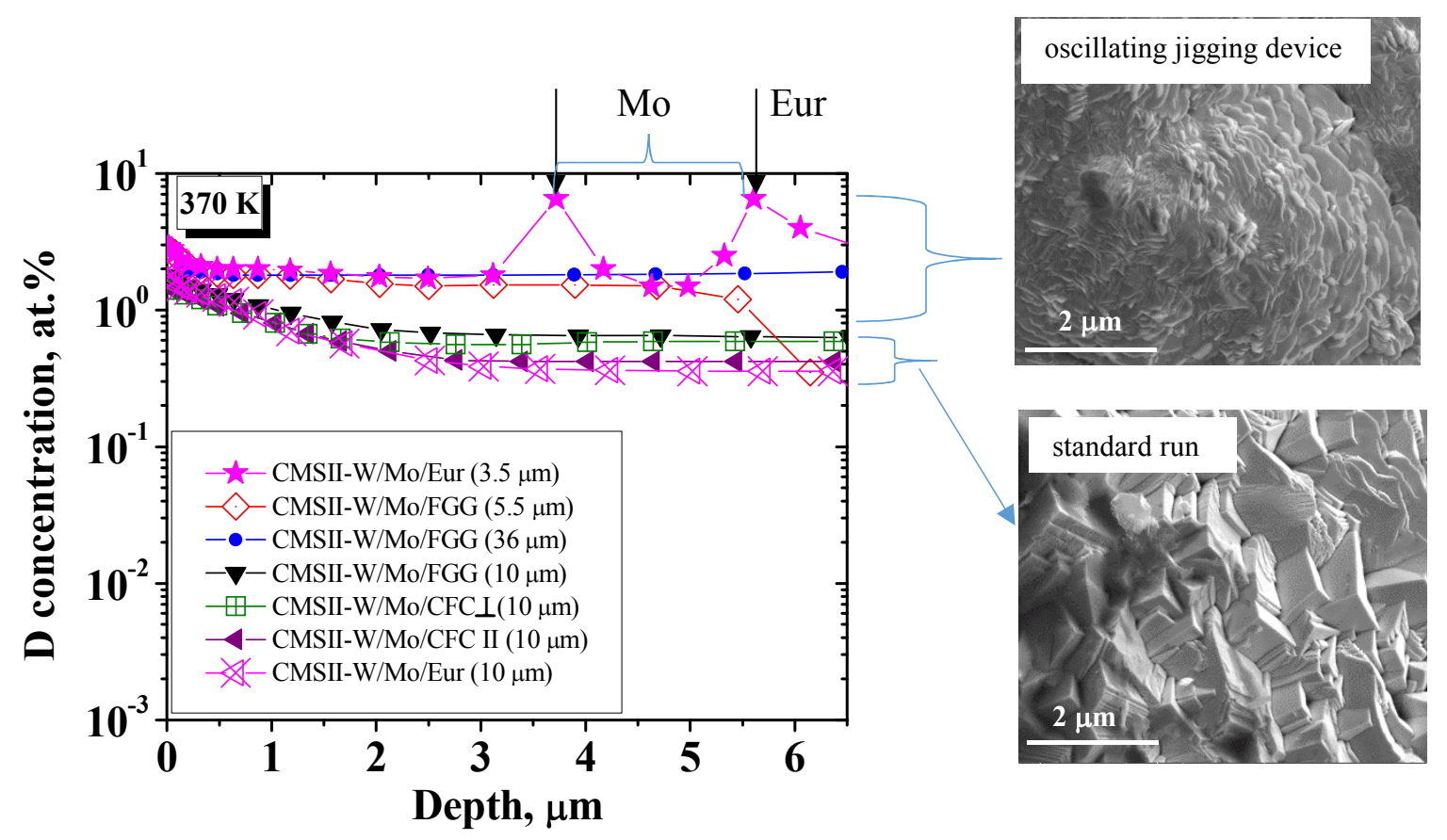

Fig. 14. D depth profiles in CMSII-W coatings with different thicknesses on Eurofer (indicated as Eur), CFC and FGG substrates. Two arrows indicate interfaces (i) between CMSII-W coating and Mo interlayer and (ii) between Mo interlayer and Eurofer substrate, respectively, in the case of CMSII-W coating with a thickness of $3.5 \mu \mathrm{m}$. SEM pictures of the different structure of coatings deposited with the oscillating jigging device and standard run are shown on the right side. Three upper curves for coatings produced with the oscillating jigging device are belong to the top SEM picture and they have smaller grain size than four bottom curves for coatings produced with standard run which are belong to the bottom SEM picture and they have bigger grain size. Deuterium was implanted in samples by ECR plasma source with ion energy of $20 \mathrm{eV}$ per D atom up to a fluence of $F=2.2 \times 10^{25} \mathrm{D} / \mathrm{m}^{2}$ at sample temperature of $370 \mathrm{~K}$. 


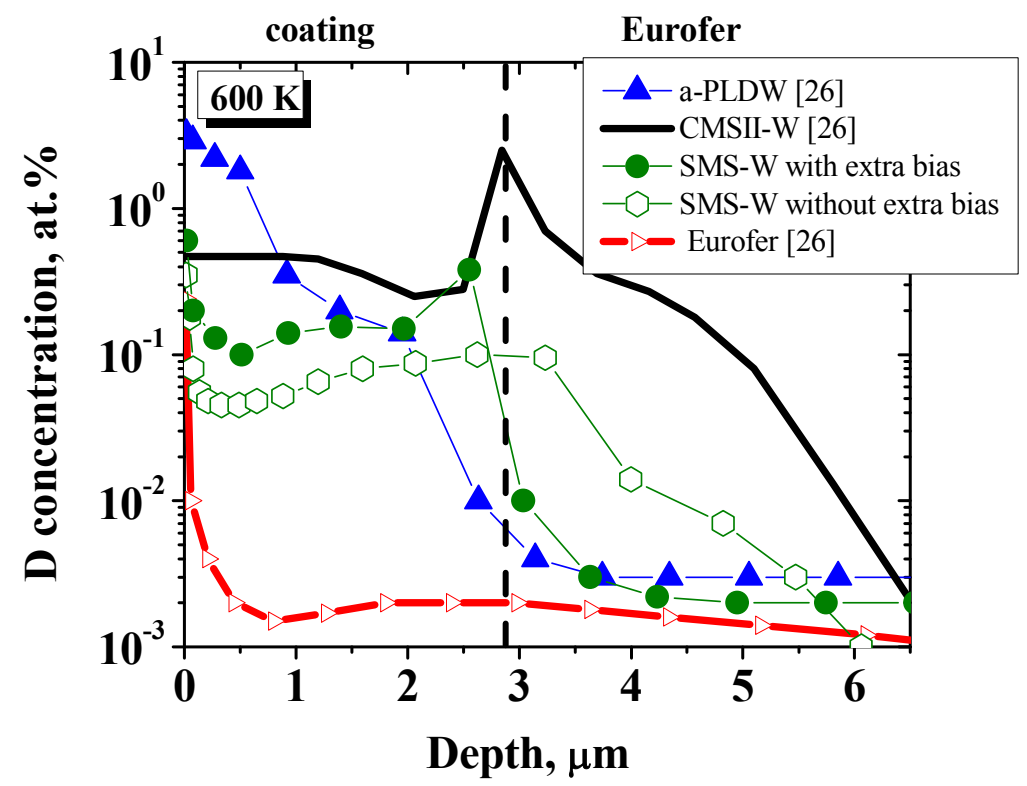

Fig. 15. $D$ depth profiles in $W$ coatings with a thickness of $\sim 3 \mu \mathrm{m}$ on Eurofer taking from [26] in comparison with new data for SMS-W coatings with and without Ar ion implantation (with and without extra bias) during the deposition. Deuterium was implanted in samples by ECR plasma source with ion energy of $20 \mathrm{eV}$ per D atom up to a fluence of $F=2.2 \times 10^{25} \mathrm{D} / \mathrm{m}^{2}$ at sample temperature of $600 \mathrm{~K}$. Dashed vertical line indicates an interface between a coating and Eurofer substrate. 


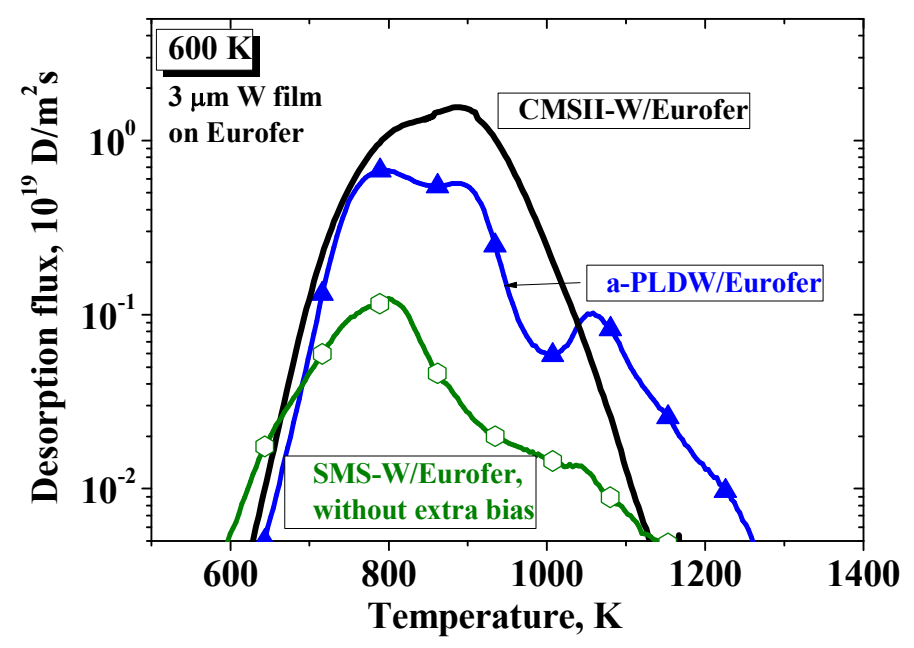

Fig. 16. TDS of $D$ from $\mathrm{W}$ coatings with a thickness of $3 \mu \mathrm{m}$ produced by different methods on Eurofer substrate after the D plasma exposure with $20 \mathrm{eV}$ at $600 \mathrm{~K}$ up to a fluence of $2.2 \times 10^{25}$ $\mathrm{D} / \mathrm{m}^{2}$ 


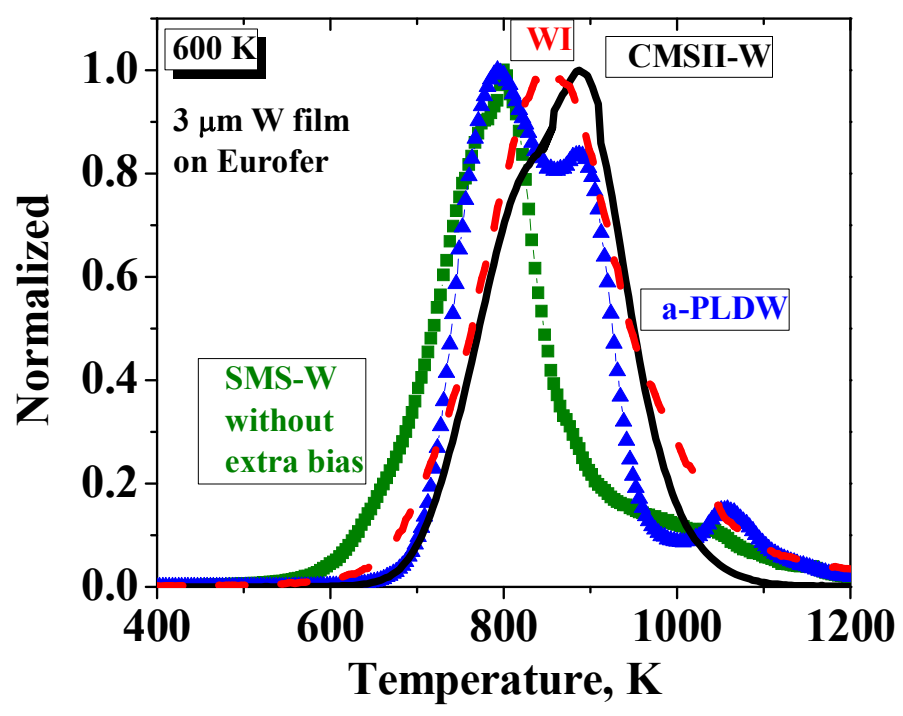

Fig. 17. Normalized TDS (from Fig. 16) of D from W coatings with a thickness of $3 \mu$ m produced by different methods on Eurofer in comparison with normalized TDS (from Fig. 8) of D from polycrystalline WI after the $\mathrm{D}$ plasma exposure with $20 \mathrm{eV}$ at $600 \mathrm{~K}$ up to a fluence of $2.2 \times 10^{25}$ $\mathrm{D} / \mathrm{m}^{2}$. 


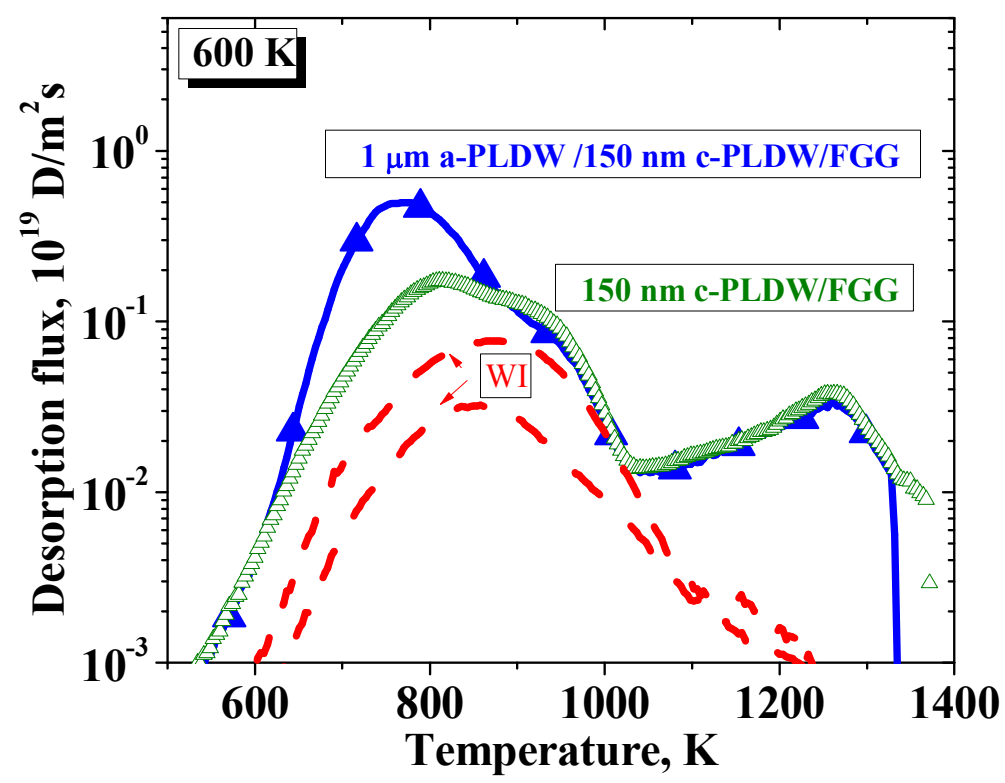

Fig. 18. TDS of D from nano-crystalline columnar-like c-PLDW coating with a thickness of 150 $\mathrm{nm}$ on FGG (150 nm c-PLDW/FGG) and amorphous-like a-PLDW coating with a thickness of 1 $\mu \mathrm{m}$ on FGG with $150 \mathrm{~nm}$ c-PLDW interlayer (1 $\mu \mathrm{m}$ a-PLDW/150nm c-PLDW/FGG). TDS of D from two polycrystalline tungsten samples, WI, are also shown for comparison. Deuterium was implanted in samples by ECR plasma source with ion energy of $20 \mathrm{eV}$ per $\mathrm{D}$ atom up to a fluence of $F=2.2 \times 10^{25} \mathrm{D} / \mathrm{m}^{2}$ at sample temperature of $600 \mathrm{~K}$. 


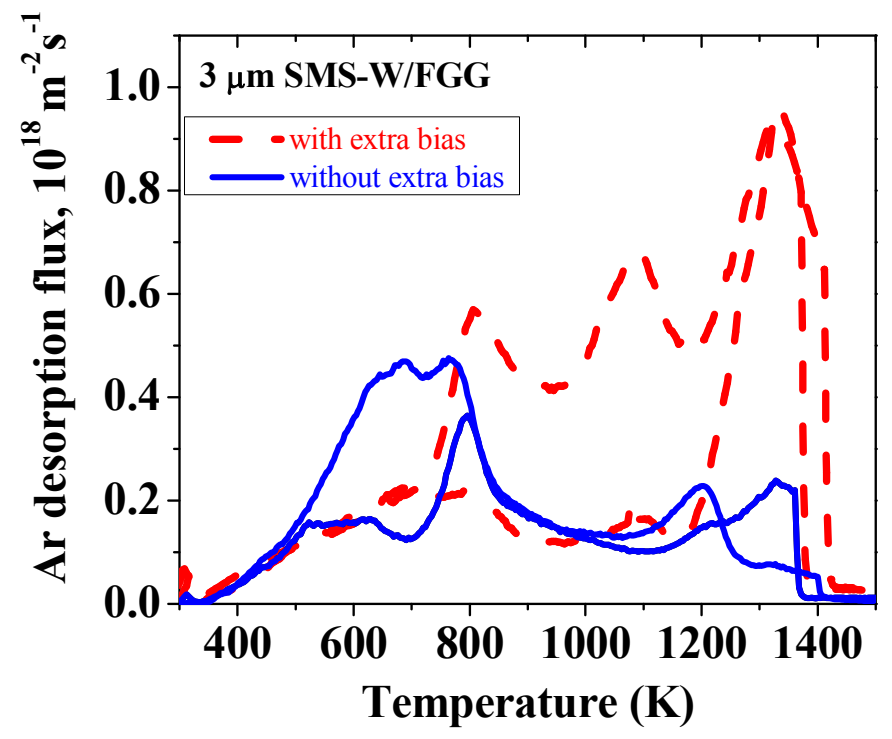

Fig. 19. Some examples of TDS of Ar from SMS-W coatings with a thickness of $3 \mu \mathrm{m}$ deposited on FGG substrate with (dashed lines) and without (solid lines) extra bias applied to the substrate. 

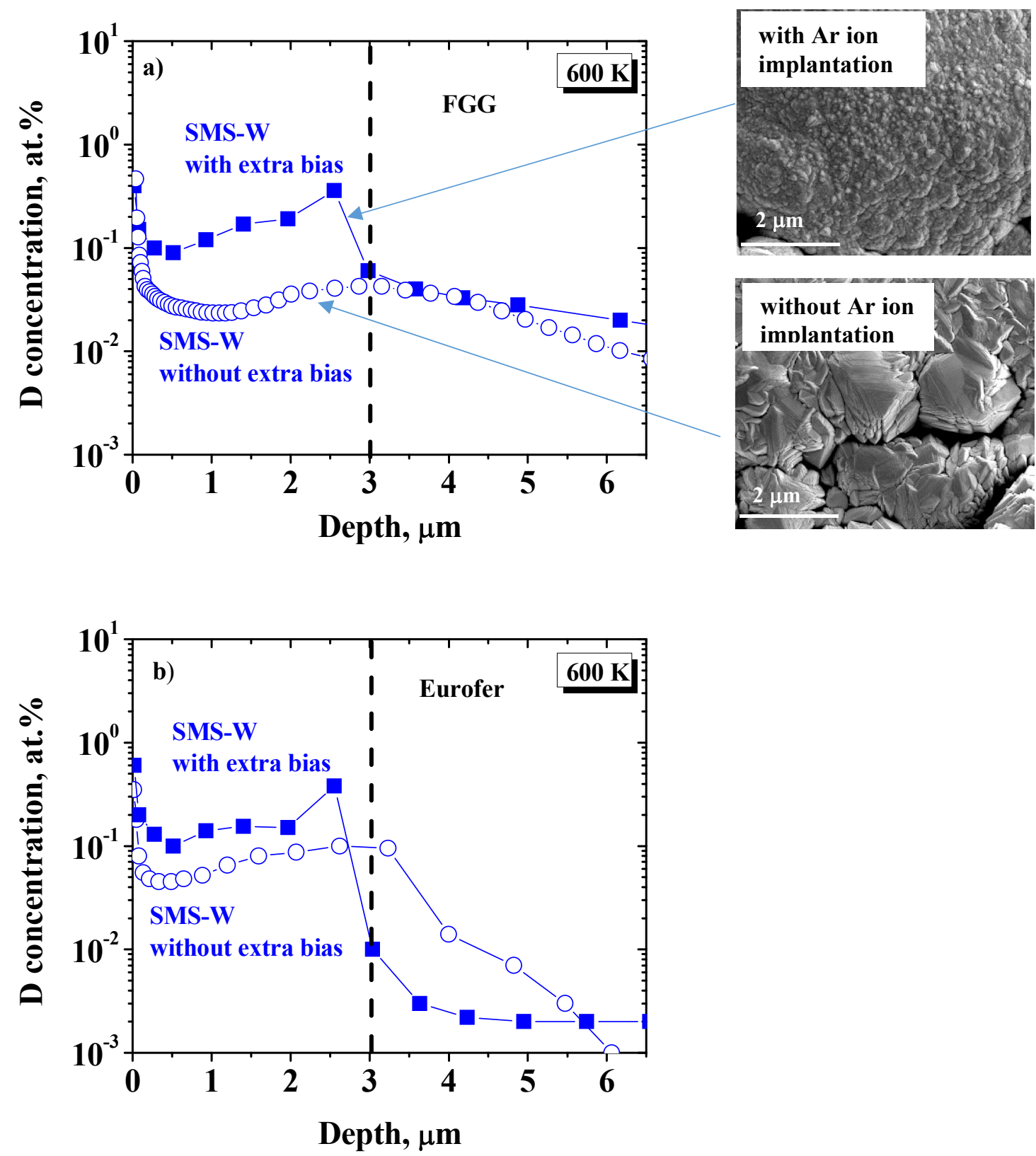

Fig. 20. $D$ depth profiles in SMS-W coating with a thickness of $\sim 3 \mu \mathrm{m}$ on a) FGG and b) Eurofer with and without Ar ion implantation during the deposition. SEM pictures of the different structure of coatings deposited with and without Ar ion implantation are shown on the right side. Deuterium was implanted in samples by ECR plasma source with ion energy of $20 \mathrm{eV}$ per $\mathrm{D}$ atom up to a fluence of $F=2.2 \times 10^{25} \mathrm{D} / \mathrm{m}^{2}$ at sample temperature of $600 \mathrm{~K}$. 


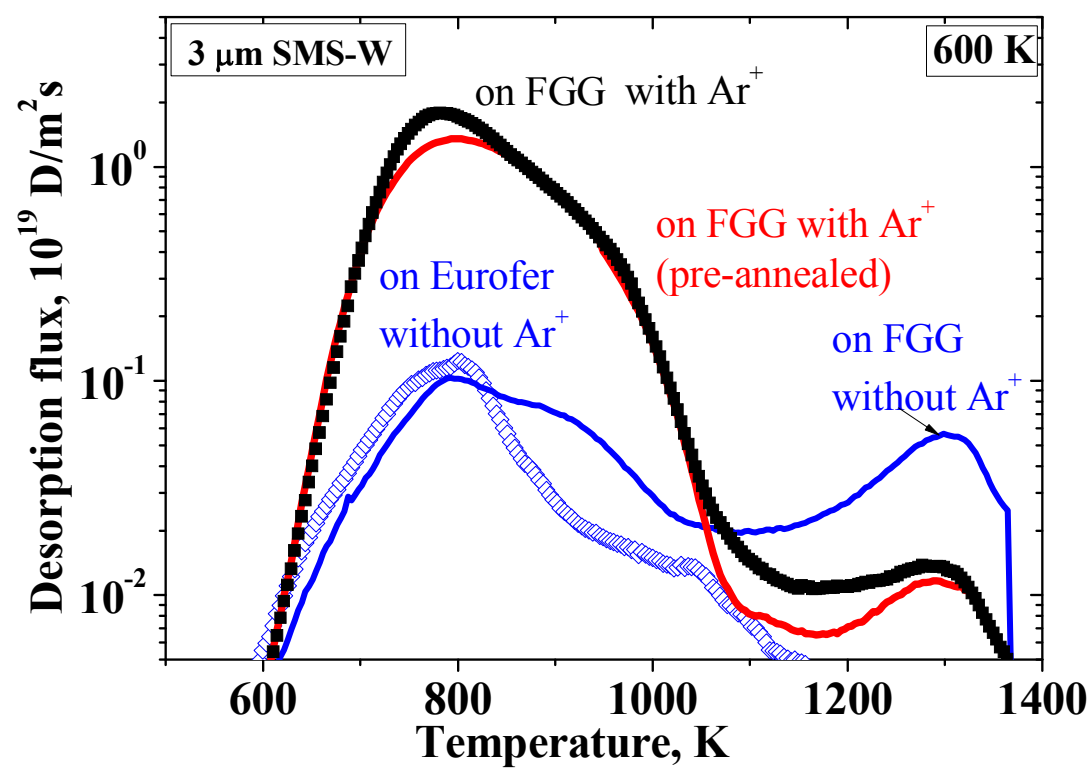

Fig. 21. TDS of D from SMS-W coatings with a thickness of $3 \mu \mathrm{m}$ deposited on Eurofer and FGG substrates. The SMS-W coatings deposited with Ar ion implantation have smaller grain size compared to SMS-W coatings deposited without Ar ion implantation. One SMS-W coating deposited with Ar ion implantation on FGG was pre-annealed at $1273 \mathrm{~K}$ for 10 minutes prior to the plasma exposure. Deuterium was implanted in samples by ECR plasma source with ion energy of $20 \mathrm{eV}$ per D atom up to a fluence of $F=2.2 \times 10^{25} \mathrm{D} / \mathrm{m}^{2}$ at sample temperature of $600 \mathrm{~K}$. 


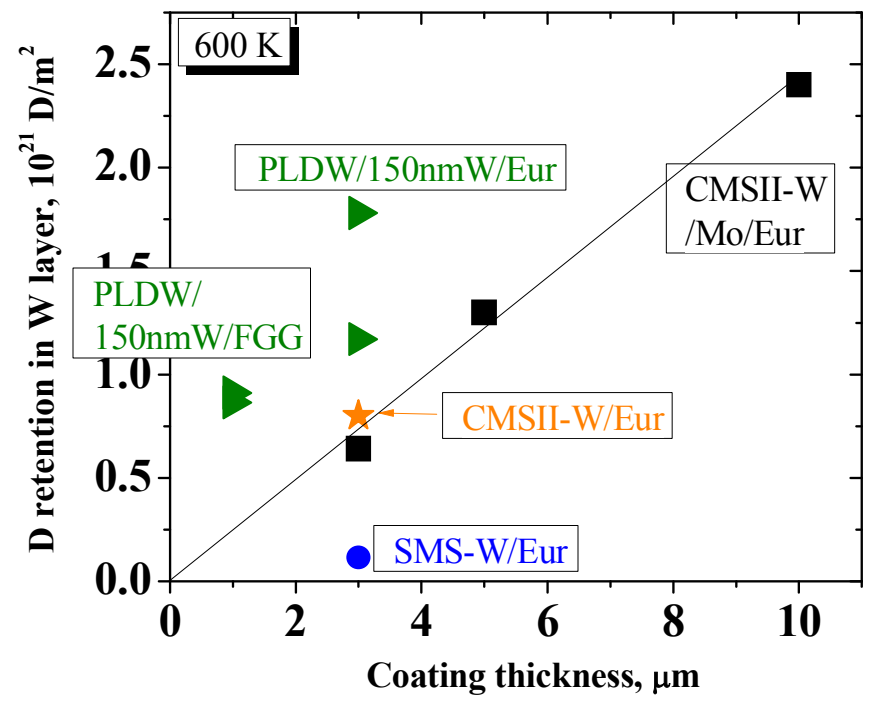

Fig. 22. The D retention in $\mathrm{W}$ coatings produced by different methods on FGG and Eurofer (indicated as Eur) after the D plasma exposure with $20 \mathrm{eV}$ at $600 \mathrm{~K}$ up to a fluence of $2.2 \times 10^{25}$ $\mathrm{D} / \mathrm{m}^{2}$ as a function of the coating thickness. The $\mathrm{D}$ retention was calculated from NRA measurements by integrating the $\mathrm{D}$ concentration over the depth of the tungsten coating. 


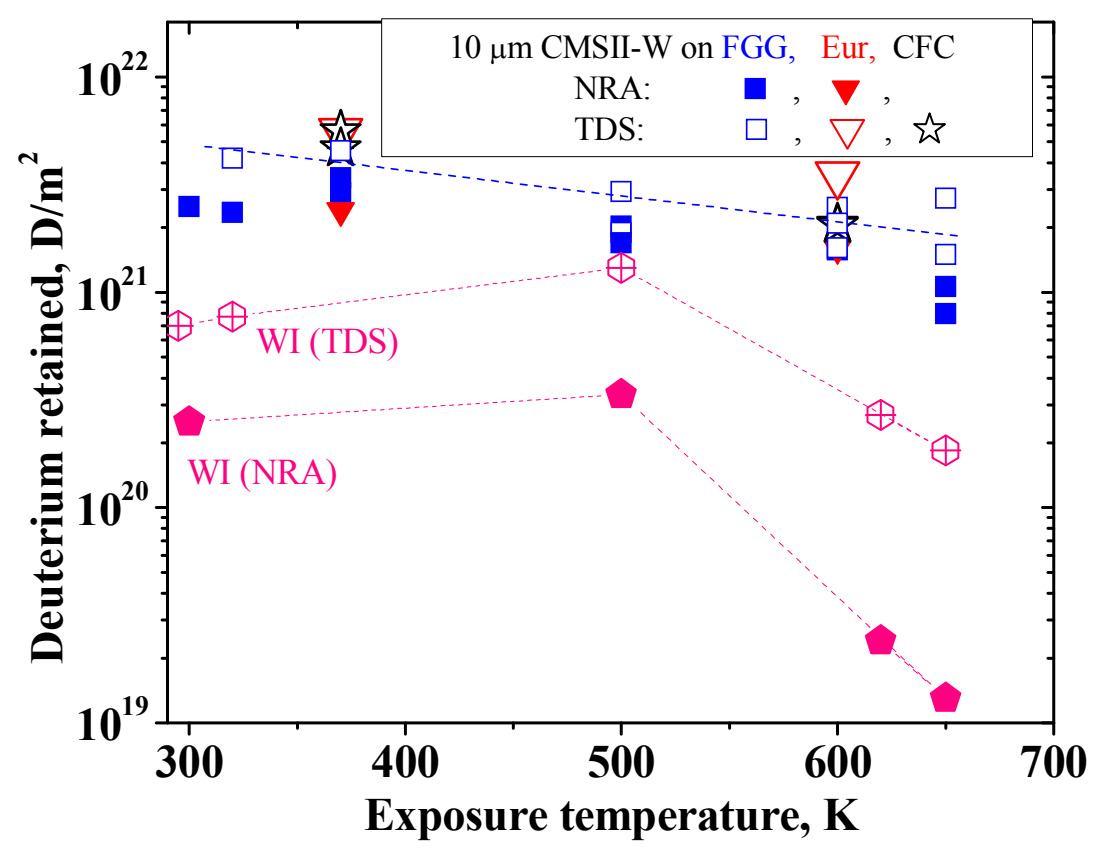

Fig. 23. The D retention in CMSII-W coating on different substrates calculated from TDS by integrating the $\mathrm{D}$ desorption rate over the time (open symbols) and from NRA by integrating the D concentration over the depth (solid symbols) in comparison with polycrystalline W ITER grade, WI. For some samples, NRA data are not shown because they coincide with TDS data. 